\title{
Reconstructing Continuous Vegetation Water Content To Understand Sub-daily Backscatter Variations
}

\author{
Paul C. Vermunt ${ }^{1}$, Susan C. Steele-Dunne ${ }^{1}$, Saeed Khabbazan ${ }^{1}$, Jasmeet Judge ${ }^{2}$, and Nick C. van de \\ Giesen $^{1}$ \\ ${ }^{1}$ Faculty of Civil Engineering and Geosciences, Delft University of Technology, 2628 CN Delft, The Netherlands \\ ${ }^{2}$ Center for Remote Sensing, Agricultural and Biological Engineering Department, University of Florida, Gainesville, FL \\ 32611 USA.
}

Correspondence: Paul C. Vermunt (p.c.vermunt@tudelft.nl)

\begin{abstract}
Microwave observations are sensitive to vegetation water content (VWC). Consequently, the increasing temporal and spatial resolution of spaceborne microwave observations creates a unique opportunity to study vegetation water dynamics and its role in the diurnal water cycle. However, we currently have a limited understanding of sub-daily variations in VWC and how they affect passive and active microwave observations. This is partly due to the challenges associated with measuring internal VWC for validation, particularly non-destructively and at timescales of less than a day. In this study, we aimed to (1) use field sensors to reconstruct diurnal and continuous records of internal VWC of corn, and (2) use these records to interpret the sub-daily behaviour of a 10-day time series of polarimetric L-band backscatter with high temporal resolution. Sub-daily variations of internal VWC were calculated based on the cumulative difference between estimated transpiration and sap flow rates at the base of the stems. Destructive samples were used to constrain the estimates and for validation. The inclusion of continuous surface canopy water estimates (dew or interception) and surface soil moisture allowed us to attribute hour-tohour backscatter dynamics to either internal VWC, surface canopy water or soil moisture variations. Our results showed that internal VWC varied with 10-20\% during the day in non-stressed conditions, and the effect on backscatter was significant. Diurnal variations of internal VWC and nocturnal dew formation affected vertically polarized backscatter most. Moreover, on a typical dry day, backscatter variations were 1.5 (HH-pol) to 3 (VV-pol) times more sensitive to VWC than to soil moisture.

15 These results demonstrate that radar observations have the potential to provide unprecedented insight into the role of vegetation water dynamics in land-atmosphere interactions at sub-daily timescales.
\end{abstract}

\section{Introduction}

The long heritage of research on remote soil moisture and biophysical parameter retrieval has shown that backscatter is sensitive to dielectric properties of vegetation, which is strongly related to its water content (Konings et al. (2019); Steele-Dunne et al. (2017)). For a long time, this sensitivity to vegetation water content (VWC) was considered a barrier to soil moisture retrieval. In the last decade however, backscatter sensitivity to VWC has been used for studies on plant hydraulics and water stress in agriculture and ecosystems (e.g. Frolking et al. (2011); Steele-Dunne et al. (2012); Schroeder et al. (2016); Emmerik et al. (2017); Konings et al. (2017); Steele-Dunne et al. (2019); El Hajj et al. (2019)). 
The increasing temporal and spatial resolution of spaceborne radar observations creates opportunities for more detailed and extensive (eco)hydrological studies. In addition to the frequent C-band Synthetic Aperture Radar (SAR) observations from Sentinel-1 (Torres et al. (2012)) and the Radar Constellation Mission (Thompson (2015)), other frequencies such as the L- and S-band mission NISAR (launch planned in 2023), the L-band mission ROSE-L (2028), and the P-band mission BIOMASS (2023) will be available within the next decade (Rosen et al. (2017); Pierdicca et al. (2019); Quegan et al. (2019)). Moreover, commercial providers such as CapellaSpace and Iceye are building satellite constellations with X-band instruments (Farquharson et al. (2021); Ignatenko et al. (2020)). These constellations will ensure multiple observations per day. As a result, the availability of spaceborne backscatter observations in the near future will offer a unique possibility to study vegetation water dynamics on different spatio-temporal scales.

However, we currently lack crucial knowledge on backscatter sensitivity to vegetation water dynamics. Soil moisture retrieval algorithms, for example, generally consider the confounding effects of vegetation water as time invariant or seasonally variant only (Kim et al. (2017)). Well-established electromagnetic models have been developed and calibrated based on seasonally variant VWC only (e.g. Bracaglia et al. (1995)). Moreover, the effect of surface canopy water (SCW), i.e. dew or rainfall interception, is also usually ignored (Vermunt et al. (2021); Xu et al. (2021)). The omission of sub-daily vegetation water dynamics causes potential retrieval errors (Brancato et al. (2017)), and more importantly, hinders our understanding of the extent to which radar backscatter could be used to monitor vegetation water dynamics. Without this knowledge, the upcoming spaceborne observations cannot be used to their full potential.

Several studies have related observed diurnal backscatter cycles to vegetation water dynamics. Clear diurnal cycles were found in tower-based observations from forest stands (e.g. Hamadi et al. (2014); Monteith and Ulander (2021)) and agricultural cropland (e.g. Vermunt et al. (2021)), as well as in aggregated satellite observations from larger forested areas (Paget et al. (2016); Emmerik et al. (2017); Konings et al. (2017)). These studies have made important contributions to the understanding of sub-daily backscatter behaviour. However, a persistent challenge is the lack of in-situ data for ground-truth validation. In-situ soil moisture can be routinely measured using a variety of sensors (Dobriyal et al. (2012); Cosh et al. (2016)). Surface canopy water can be measured continuously using leaf wetness sensors (Cosh et al. (2009); Vermunt et al. (2021)). However, internal VWC is still generally measured using laborious destructive sampling, particularly in agricultural fields (e.g. Vreugdenhil et al. (2018); Emmerik et al. (2015); Ye et al. (2021)). This is unavoidable for monitoring seasonal changes, but is prohibitively timeconsuming and labor-intensive for sub-daily variations. Hence, it is crucial to find a more efficient way to obtain continuous, quantitative estimates of sub-daily VWC variations.

In this study, we aim to gain a better understanding of what controls sub-daily backscatter variations from a corn field by using unique estimates of moisture fluctuations in the vegetation and soil. This is achieved by first estimating continuous records of VWC using field sensors. Specifically, we adapted a methodology developed by the tree physiology community, described in section 2, to estimate 15-minute changes in corn VWC using sap flow sensors and a weather station. We used data from in-situ sensors to account for the influence of surface soil moisture and surface canopy water (SCW). Finally, we used tower-based L-band backscatter observations and the resulting VWC records to demonstrate the effect of sub-daily VWC variations on backscatter. 


\section{Estimating diurnal variations in internal vegetation water content}

Diurnal variations of internal VWC have been estimated in trees before, mainly in studies focused on understanding the functional role of stem water reserves on daily tree water use. A well-established in situ method uses sap flow probes at the base of the stem and in the crown (e.g. Goldstein et al. (1998); Meinzer et al. (2004); Čermák et al. (2007); Phillips et al. (2008); Köcher et al. (2013)). This method is based on the time lag between transpiration and basal sap flow, as a result of a tree's hydraulic capacitance, which is the change in water content per unit change in water potential (e.g. $\left.\mathrm{kg} \mathrm{MPa}^{-1}\right)(\mathrm{Goldstein}$ et al. (1998); Oguntunde et al. (2004)). Morning transpiration, driven by the atmospheric evaporative demand, causes depletion of internal VWC in the crown, and, depending on the hydraulic capacitance, a drop in water potential. In response to the resulting potential gradient, sap flow rates increase to replenish the depleted VWC. As long as transpiration rates exceed basal sap flow rates, water is withdrawn from internal VWC, and when basal sap flow exceeds transpiration, internal VWC is refilled. Consequently, the diurnal variation in tree VWC could be calculated from the cumulative differences between whole-crown transpiration and basal sap flow.

Whole-crown transpiration was estimated from branch and basal sap flow, based on two assumptions. First, time lags between branch sap flow in the crown and transpiration were assumed to be negligible compared to time lags between branch and basal sap flow. Hence, the averaged daily cycles of sap flow in the monitored branches were assumed to approximate the cycles of whole-crown transpiration. Secondly, most studies assumed the whole-crown transpiration to equal basal sap flow during a 24 hour period (Goldstein et al. (1998); Čermák et al. (2007); Phillips et al. (2008); Köcher et al. (2013)). This assumption made it possible to estimate whole-crown transpiration rates by first dividing averaged branch sap flow by its daily sum, and then multiplying by the daily sum of basal sap flow. The corresponding assumption is that all water that is withdrawn from internal VWC is replaced within 24 hours.

Here, we investigate the potential of this sap flow method for estimating diurnal VWC in corn plants. The largest differences between corn plants and trees are related to hydraulic capacitance and structure. Corn plants have much lower hydraulic capacitance than most trees (Langensiepen et al. (2009)), and hence shorter time lags between transpiration and basal sap flow. As a consequence, installing a sap flow sensor as a surrogate for transpiration would be problematic, since the assumption of negligible time lag between upper sap flow and transpiration compared to basal sap flow is invalid. Moreover, transpiring corn leaves are somehow evenly distributed across the stem, in contrast to trees with a crown, which makes the placement of a second sensor to represent transpiration nearly impossible. For these reasons, we derived transpiration from indirect estimates of reference evapotranspiration instead.

\section{Materials and Methods}

\subsection{Experimental sites}

The data for this study were collected during two field campaigns conducted in 2018 (Florida, USA) and 2019 (The Netherlands), both concerned with microwave observations of corn. The field campaign in Florida was conducted in Citra (29.410N, 
82.179W), at the Plant Science Research and Education Unit (PSREU) of the University of Florida and the Institute of Food and Agricultural Sciences (UFIFAS). Sweet corn was planted on a sandy soil with a density of 7.9 plants $\mathrm{m}^{-2}$, and harvested after 66 days in mid-June for human consumption. The climate of this area in Florida is humid subtropical, and the 2018 spring growing season was characterized by high temperatures, high-intensity rainfall and thunderstorms.

The field campaign in The Netherlands was conducted in Reusel (51.319N , 5.173E), at Van den Borne Aardappelen. There, field corn, with a typical longer growing season, was planted on a sandy soil with a density of 8 plants $\mathrm{m}^{-2}$, and harvested for silage after the required senescence, 148 days after planting. The Netherlands has a more temperate maritime climate. However, maximum temperature records were broken close to the field site during the growing season of 2019, and it was the second anomalously dry summer in a row (Bartholomeus et al. (2020)).

\subsection{Data collection}

\subsubsection{Sampling vegetation water content and monitoring crop growth}

Vegetation water content (VWC) was measured by destructive sampling. Six to eight field-representative samples were taken from designated sampling areas. Any present dew or interception was removed with paper towels before the samples were weighted to determine average fresh biomass per plant in $\mathrm{kg}\left(m_{f}\right)$. Samples were oven-dried at $60{ }^{\circ} \mathrm{C}$ for $4-8$ days, depending on growth stage. These dried samples were weighed again to determine average dry biomass per plant in $\mathrm{kg}\left(m_{d}\right)$. Fieldrepresentative VWC $\left[\mathrm{kg} \mathrm{m}^{-2}\right]$ was estimated by multiplying the evaporated water per plant $[\mathrm{kg}]$ with the number of plants per $\mathrm{m}^{2}\left(\rho_{\text {plant }}\right)$, see equation 1 .

$V W C=\left(m_{f}-m_{d}\right) \rho_{\text {plant }}$

In order to minimize the effect of day-to-day weather variations, seasonal VWC variations were monitored by predawn sampling: three times per week in 2018, and one or two times per week for the slower growing corn in 2019. In 2018, predawn (6am) measurements were supplemented with 6pm measurements once a week, to capture differences between morning and evening passes for a sun-synchronous satellite such as SMAP (Entekhabi et al. (2010)). In 2019, we aimed to capture full diurnal cycles of VWC. Hence, we sampled on five equally distributed times between sunrise and sunset, on 14 days.

In both campaigns, crop development was monitored 1-3 times per week. In addition, leaf areas were estimated using regular measurements of leaf widths and lengths and the assumption that corn leaves are perfectly elliptically shaped. Leaf area index (LAI) was calculated by multiplying a single plant's estimated leaf area with plant density.

\subsubsection{Sap flow}

Sap flow was monitored using stem-flow gages produced by Dynamax Inc. (Houston, TX, USA). The measurement is based on the stem heat balance theory (Sakuratani (1981)). A flexible collar strap with built-in heater strip and thermocouples is wrapped around a corn stem, about $20 \mathrm{~cm}$ above the ground, and then isolated and protected from environmental conditions such as 
rain and radiation. The entire circumference of the stem receives a constant heat input from the heater strip. As sap movement carries heat, thermal dissipation corresponds to the sap flow rate. Therefore, the change in temperature is used as a tracer for sap flow [ $\mathrm{g} \mathrm{hr}^{-1}$ ], thereby taking into account the heat transfer to the stem tissue and the ambient air. Conversion to mm $15-$ minute $^{-1}$ was performed using the density of liquid water and the planting density. Because the collar straps are designed to fit a certain range of stem diameters, we collected data in mid- and late season. In 2018, four sensors were installed simultaneously on four different plants and data were averaged. In 2019, only two sensors were installed due to power limitations, and one failed. Gaps in the time series were caused by disturbances in the connection with the battery or solar panel. Because of these battery issues, there were only three matches for full day sap flow and full day sampling in 2019: July 25, August 23, and August 28.

\subsubsection{Transpiration}

In 2018, 15-min meteorological data were obtained from the nearby Florida Automated Weather Network (FAWN) weather station, located within $600 \mathrm{~m}$ from the experimental field. Observations of rainfall, air temperature ( $2 \mathrm{~m})$, solar radiation, relative humidity and wind speed were downloaded from the Report Generator ${ }^{1}$. In 2019, a weather station was installed on the edge of the experimental site, with a ECH2O Rain Model ECRN-100 rain gauge, Apogee SP-212 pyranometer (solar radiation), a Davis Cup anemometer (wind and gust speed, and wind direction), and a HOBO Temperature/RH Smart Sensor Model S-THB-M008 (temperature and relative humidity). Reference evapotranspiration (ETo) was estimated using the Penman-Monteith approach described by Zotarelli et al. (2010).

A widely used approach to derive transpiration from ETo is a linear conversion using crop factors, e.g. the FAO-56 dual crop coefficient model Allen et al. (1998). However, in many cases, these estimations systematically over- or underestimate direct observations of transpiration (Ding et al. (2013); Rafi et al. (2019)) or sap flow (Langensiepen et al. (2009)), while basal sap flow and transpiration at the leaves must equal over a sufficiently long time period (Swanson (1994)). For our data sets, Penman-Monteith derived transpiration (Allen et al. (1998)) is systematically lower than measured sap flow. Consequently, we chose to estimate transpiration from ETo and sap flow measurements.

The approach is similar to rescaling branch sap flow as described in section 2. First, transpiration was assumed to equal basal sap flow during a 24 hour period, and 15-minute ETo estimates were divided by their 24-hour sum and then multiplied by the 24-hour sum of basal sap flow. However, the assumption of complete replacement of withdrawn water within 24 hours may not always hold. Therefore, we also tested the effect of relaxing this assumption, and using multiple days instead: 3 , 5 or 7 consecutive days surrounding the day of interest, or all measured days in the data set. Both approaches assume a simple, linear relation between ETo and transpiration. It will be shown that this assumption can cause an offset between the timing of the diurnal cycles of sampled and reconstructed VWC. This issue was addressed by adopting the cumulative distribution function (CDF) matching method, previously used to rescale satellite-derived surface soil moisture to observations (Reichle and Koster (2004); Drusch et al. (2005); Brocca et al. (2011)). This non-linear approach removes systematic differences between two data sets by matching the CDF's of both data sets (Brocca et al. (2011)). Here, we matched the CDF of ETo to the CDF of sap flow.

\footnotetext{
${ }^{1}$ https://fawn.ifas.ufl.edu/data/reports/
} 
This matching was achieved by first ranking both data sets from low to high values, and then fitting a second-order polynomial function through the scatter plot of both ranked data sets. Subsequently, this function was used to convert the 15-min ETo data to transpiration estimates. CDF-matching was also performed for 1, 3, 5, 7 consecutive, and all available days.

\subsubsection{Surface canopy water and soil moisture}

Surface canopy water (dew, interception) was monitored using PHYTOS 31 Leaf Dielectric Wetness sensors. Three sensors were installed on different heights in the vegetation layer. Details of sensors and sensor output conversion to SCW [kg m$\left.{ }^{-2}\right]$ are described in Vermunt et al. (2021).

Soil moisture $(\theta)$ was observed in two pits with 15-minute resolution, using EC-5 sensors on 5, 10, 20, 40 and $80 \mathrm{~cm}$ depth. These measurements were averaged based on depth. The averaged measurement at $5 \mathrm{~cm}$ depth was used as estimate of surface soil moisture for interpreting backscatter data. In addition, root zone soil moisture was estimated by integrating the measurements from all depth over a soil column of $100 \mathrm{~cm}$, based on the thickness of the soil layer associated with the depth of the sensor.

\subsubsection{L-band scatterometer data}

High temporal resolution L-band backscatter data were collected with the polarimetric University of Florida L-band Automated Radar System (UF-LARS) throughout the growing season of 2018. This system was mounted on a Genie manlift at a height of $14 \mathrm{~m}$ above the ground. The scatterometer scanned the corn field with an incidence angle of $40^{\circ}$, and acquired 16 observations per day in the late season. The previously mentioned installation of sensors and vegetation sampling was performed outside the arc swept by the radar. A comprehensive description of the observations and the UF-LARS system can be found in Vermunt et al. (2021) and Nagarajan et al. (2014), respectively. Cross-pol is used to refer to the average of the HV- and VH-polarized backscatter.

\subsection{Reconstructing 15-minute variations of Vegetation Water Content in corn}

175 The methodology used to estimate 15-minute changes in corn VWC is based on the method used for trees described in section 2, with the difference that we derived transpiration from indirect estimates of reference evapotranspiration (see 3.2.3 and equation 2).

$V W C_{r e c}(t)=V W C_{t_{0}}+\sum_{k=15 \min }^{t-t_{0}}\left(\left(F_{k}-T_{k}\right) \Delta t\right)$

, where $V W C_{r e c}(t)$ is the reconstructed $\mathrm{VWC}$ at time $\mathrm{t}$, and $V W C_{t_{0}}$ is the reference $\mathrm{VWC}$ (e.g. the predawn measurement) which serves as a constraint for the reconstruction. $F$ is sap flow, $T$ is transpiration, both converted to $\mathrm{kg} \mathrm{m}^{-2}$ per 15 minutes, $\Delta \mathrm{t}$ is the 15 -minute time step, and $t-t_{0}$ is the time between $\mathrm{t}$ and $t_{0}$ in minutes. 
The sampled diurnal VWC cycles from the 2019-campaign (Section 3.2.1) were used to validate the method. July 25, August 23 and August 28 were the days for which both these samples and the other input data for the reconstruction were available. For these days, we used one of the five sampling times to constrain the daily cycle $\left(V W C_{t_{0}}\right.$ in eq. 2$)$. The other four independent samples were compared against the reconstructed VWC cycle. For each day, we calculated the Root Mean Square Error (RMSE) between the four independent samples and reconstructed VWC on the four sampling times. All five samples were used as $V W C_{t_{0}}$ once to determine the best time to constrain the reconstruction.

Finally, a 10-day time series of VWC from the 2018-campaign was reconstructed to support the analysis of variations in the L-band backscatter collected during that campaign (Section 3.4). This time series contained five sampling days. On these days, samples were used to constrain the VWC record. On the five days without sampling, the VWC records were constrained either at the end of previous sampling day (forward reconstruction), or the start of next sampling day (backward). In case these forward and backward reconstructions did not overlap, the average of both was considered the best estimate of VWC.

\subsection{Interpreting the behaviour of sub-daily L-band backscatter}

Sub-daily L-band backscatter behaviour was analyzed by using continuous time series of: (1) VWC inside the corn plants, (2) surface canopy water (SCW), and (3) surface soil moisture $(\theta)$. The longest period for which we had all data available was from June 4 00:00 to June 13 10:15. During this period, the corn is at maximum height and LAI, and 1-2 weeks before harvest on June 18. All analyses were conducted for this period.

The separate effects of the different moisture stores (VWC, soil moisture, and SCW) on backscatter $\left(\sigma^{0}\right)$ were quantified through multiple linear regression. The relation between backscatter and these dynamic moisture stores was described by:

,where $t_{0}$ is the first measurement time of the day (01:00), and assuming linear relations between $\sigma^{0}$ and the individual

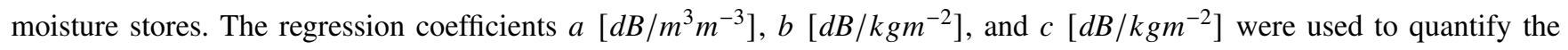
change in backscatter as a result of change in moisture, and were derived for each polarization separately.

\section{Results}

\subsection{Seasonal and diurnal variation of vegetation water content}

Fig. 1 illustrates the seasonal and diurnal variations of VWC $\left[\mathrm{kg} \mathrm{m}^{-2}\right]$ as a result of destructive sampling in the 2018 and 2019 campaigns. From early to mid-season, VWC increased as a result of biomass accumulation. The field corn from 2019 was allowed to senesce before harvest, resulting in a significant reduction of water storage in the plants from August 23 onward. The sweet corn from 2018 was harvested before considerable senescence.

The open markers are the non-predawn measurements, which were at 18:00 (2018) and at four evenly distributed times between sunrise and sunset (2019). The range of these latter diurnal measurements gives an indication of the amplitude of the 

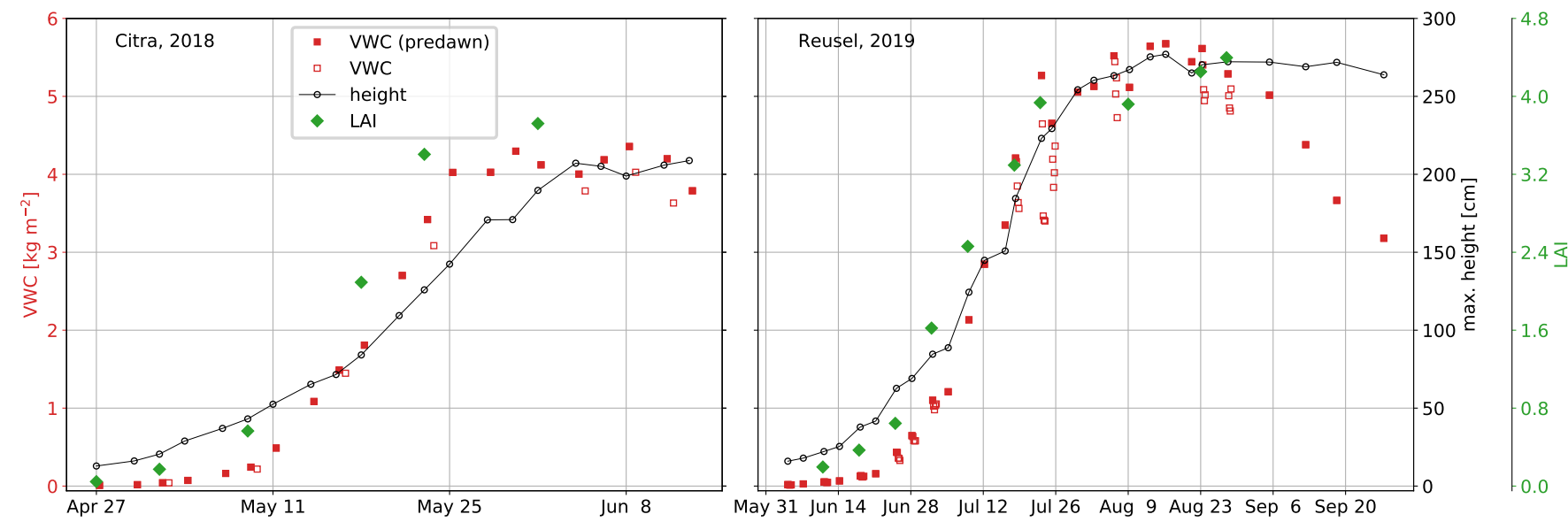

Figure 1. Vegetation Water Content (VWC), crop height and leaf area index (LAI) from the field experiments in Citra (2018) and Reusel (2019). Filled red markers indicate predawn measurements, while open markers indicate non-predawn measurements at 18:00 (2018) and morning to sunset (2019).

daily cycle of VWC. On most days, the diurnal minimum was 10-20\% lower than predawn water storage. An exception was July 23 , on which predawn water storage was depleted by $35.4 \%$ during the day. Fig. 2 zooms in to mid-season measurements, and illustrates the difference between water depletion in the non-stressed conditions compared to the stressed date. The photograph was taken around the third measurement on July 23. This picture shows leaf 'rolling', a mechanism to reduce the leaf area exposed for transpiration, and a sign of drought stress. Normal-shaped leaves were observed again as a result of irrigation, which was applied right after the last sampling on July 23 in order to ensure the crop's survival.
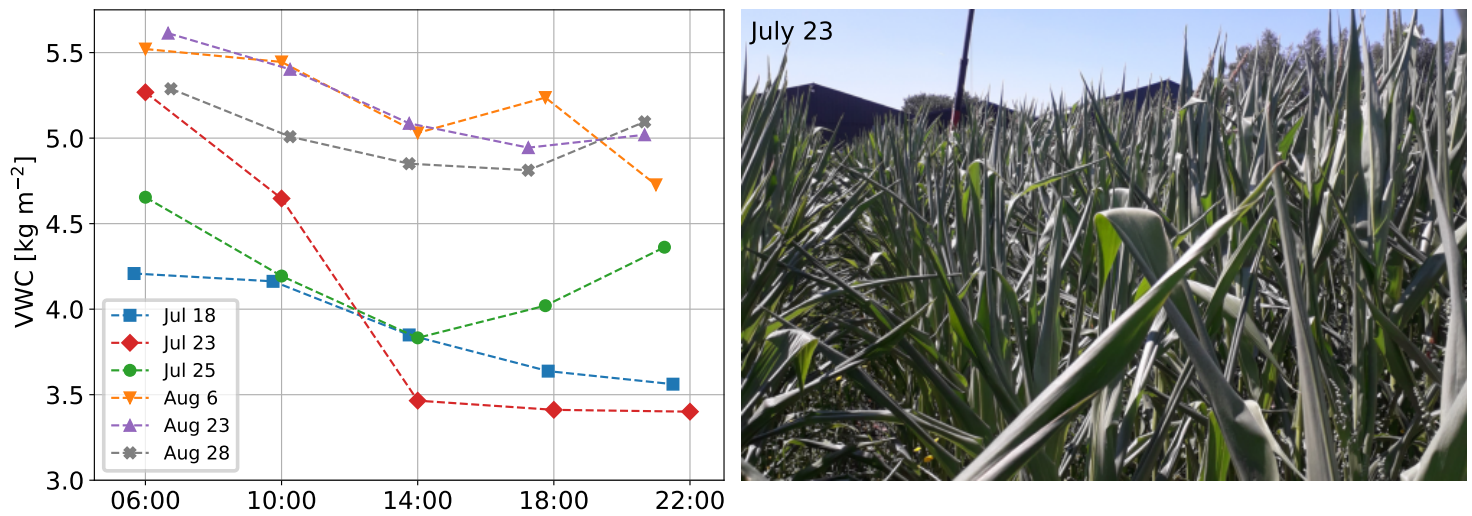

Figure 2. Sampled vegetation water content (VWC) in the mid-season, 2019 (left), and a picture of 'rolled' leaves (right), taken around the third measurement on July 23, as a sign of drought stress. 


\subsection{Reconstructions of sub-daily variations in vegetation water content}
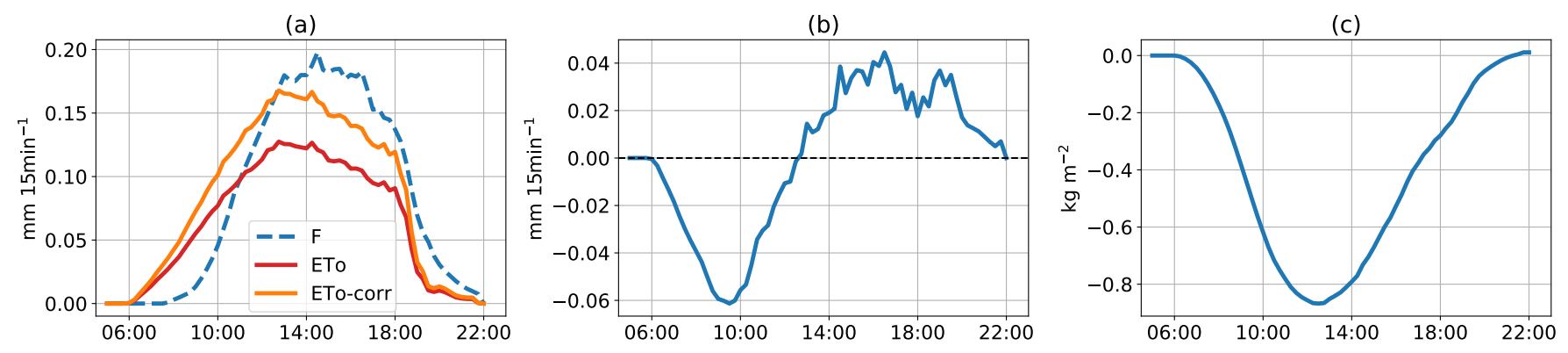

Figure 3. Three step procedure to reconstruct the diurnal variation in VWC: example for July 25, 2019. Fig. (a) shows the daily cycles of sap flow (F), reference evapotranspiration (ETo), and the linearly corrected ETo (ETo-corr), which is the transpiration estimate, (b) is the difference between sap flow and transpiration, where negative values indicate depletion of water storage, and positive values indicate refill, and (c) illustrates the resulting cumulative change in stored water $\triangle \mathrm{VWC})$ during the day.

The procedure to reconstruct 15-min changes in VWC is depicted in Fig. 3. Here, the simplest, linear estimate of transpiration (see 3.2.3) was used. Fig. 3(a) shows the diurnal cycles of basal sap flow (F), reference evapotranspiration (ETo), and the corrected ETo (ETo-corr), which is the transpiration estimate, on July 25, 2019. On this day, which was particularly warm and sunny, we measured a maximum temperature of $39.0{ }^{\circ} \mathrm{C}$ in the field. The difference between sap flow and transpiration gave the estimated depletion and refilling of internal water storage (b). If transpiration rates exceeded sap flow rates at some point in time, the line is below zero, which indicates a depletion of water storage. Positive values indicate refilling. Finally, the cumulative difference between sap flow and transpiration represents the diurnal change in plant water storage, or $\Delta \mathrm{VWC}$ (c). The minimum VWC was reached around 12:45, when $0.87 \mathrm{~kg} \mathrm{~m}^{-2}$ of the predawn water storage was depleted. This is close to the maximum diurnal difference of $0.82 \mathrm{~kg} \mathrm{~m}^{-2}$ observed from destructive sampling (Fig. 2).

Fig. 4 shows the procedure of estimating transpiration using the non-linear CDF-matching principle, as an alternative to the linear correction shown in Fig. 3. Again, we take July 25, 2019, as an example, with the difference that we use the data from July 24 and 26 as well (a). Fig. 4(b) illustrates the difference between the CDF's of sap flow and ETo, which is particularly evident at the $35 \%$ highest rates. At lower rates $\left(<0.07 \mathrm{~mm} 15-\right.$ minute $\left.^{-1}\right)$, ETo rates were slightly higher than sap flow rates. As these systematic differences between both rates may be unrealistic, a second-order polynomial was fitted through the scatter plot with ranked ETo and sap flow data (c), and was used to match the CDF's (d). The resulting ETo-cdf (e) was used to estimate $\triangle \mathrm{VWC}$ at any point in time using the approach described in Fig. 3.

Diurnal cycles of VWC were reconstructed for both linear and non-linear approaches to estimate transpiration, using $\Delta$ VWC (Fig. 3(c)) and one destructive sample (Fig. 1,2) per day as a constraint. Results were compared against destructive samples from both field campaigns. The effect of both the time of the constraint, as well as the number of days considered for transpiration estimation, on the VWC reconstructions were evaluated. The RMSE's of the 2019 data are presented in tables A1-A2 in the Appendix. A general optimal combination of time of constraint and number of days to consider could not be found. 
(a)

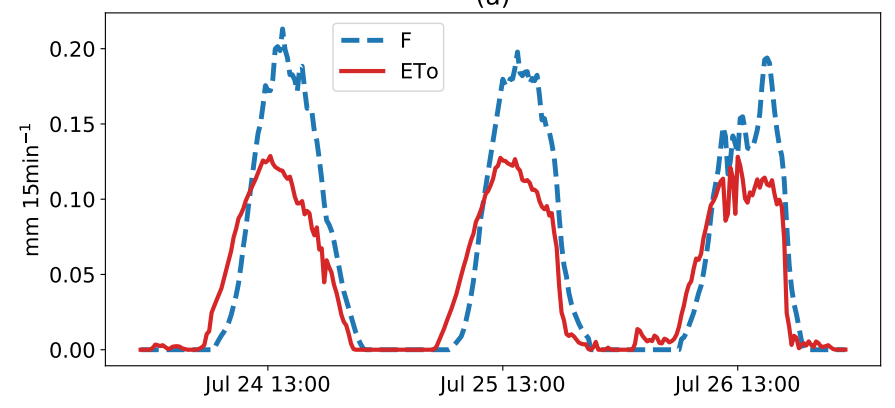

(d)

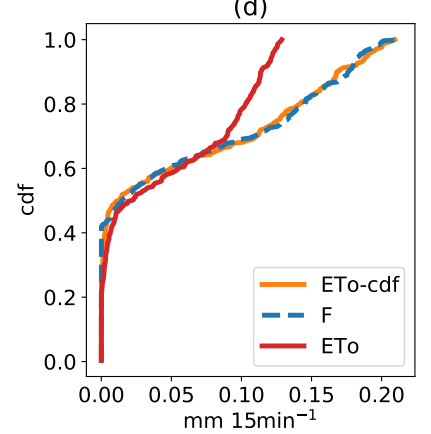

(b)

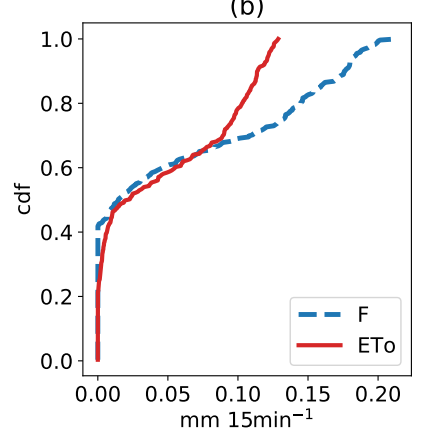

(e)

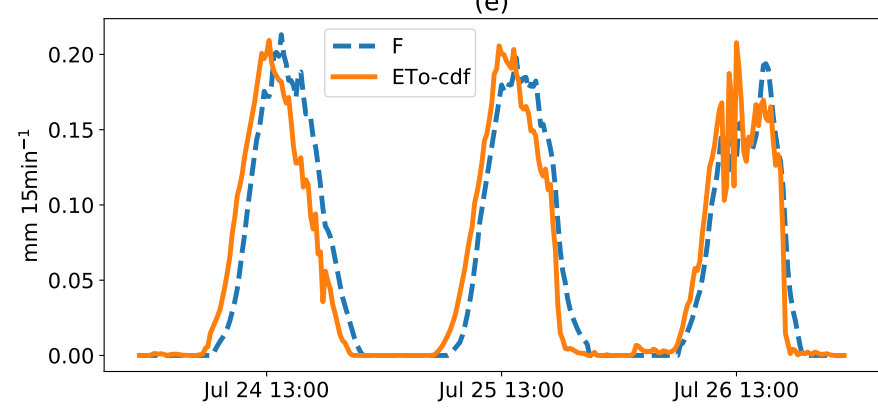

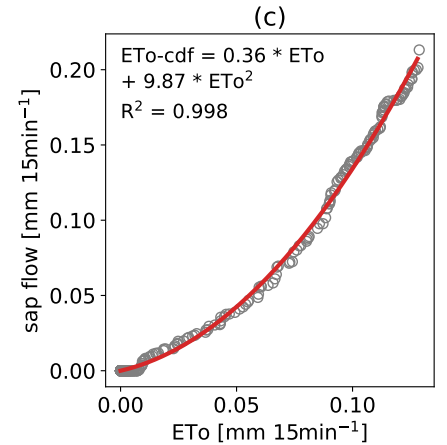

Figure 4. Example of ETo rescaling to approximate transpiration (2019 campaign), using the CDF matching approach. (a) sap flow (F) and reference evapotranspiration (ETo) data from July 24-26, 2019, (b) cumulative distribution function (CDF) of both data sets in this period, (c) $2^{\text {nd }}$ order polynomial fit through ranked $\mathrm{F}$ and ETo data, used to derive the CDF-matched ETo (ETo-CDF), which was added to the CDF plot in (d). (e) shows the final result of the CDF-matching.

However, in general, better agreements between samples and reconstructions were found when the reconstructed estimates were not constrained with samples taken at the limits of the diurnal cycle (i.e. predawn and sunset), but rather with morning, afternoon or evening samples. An exception to this rule was July 25, when all available data for the CDF-matching were used. Using CDF-matched transpiration estimates resulted in a better agreement with the destructive sampling data than using linear correction in $80 \%$ of the cases. The best reconstructions from 2019 (Tables A1 and A2), are presented in Fig. 5, differentiated by the approach to estimate transpiration. Differences between environmental conditions are shown in Fig. 6 . Fig. 5 illustrates the improvement of the reconstruction when using more than one day of data for the estimation of transpiration (second and third row). Besides, the reconstruction on July 25 illustrates the possible improvement CDF-matching can have. On July 25 and August 28, the RMSE's of the lowest plots were 8 and 12\% of the amplitude of the diurnal cycles, respectively. On August 23 , the agreement is poor, especially later in the day, and this percentage is $36.9 \%$. On this day, reconstructions and samples disagree for all three approaches to estimate transpiration, but less so for the CDF matching procedure.

For the 2018 campaign, we had a maximum of two VWC samples per day. Table A3 shows the offset between one of the samples and the reconstructed VWC, which was constrained by the other sample, for June 4,8 and 11 . The lowest offsets were 
found when transpiration was estimated using all data (12 days), and when CDF-matching was applied. Consequently, we used the transpiration calculated based on this combination for further use of reconstructed VWC.
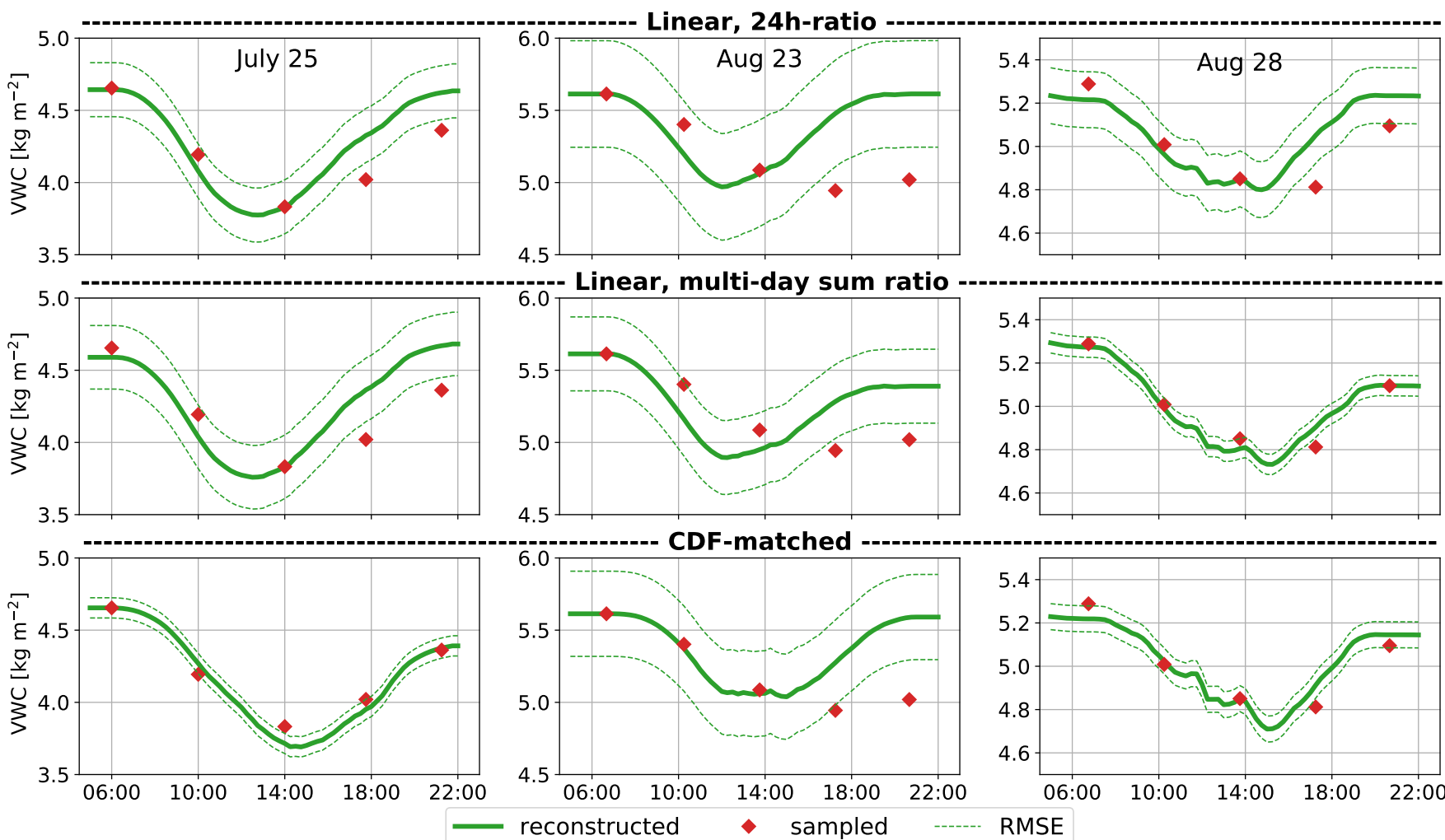

Figure 5. Best diurnal VWC reconstructions for July 25, August 23 and August 28 (2019) for three different methods of estimating transpiration. The upper row shows the results for using the simplest, linear estimate of transpiration. The middle row shows the reconstructions using linear estimates of transpiration, but now considering three, five and seven days rather than 24 hours. The lower row shows the results after cdf-matching, considering all data, five days and three days for the CDF-matching, respectively. The dashed green lines respresent one RMSE above and one RMSE below the reconstructed VWC.

\subsection{Reconstructing a record of multiple days}

Fig. 7 shows the procedure for reconstructing the 10-day VWC record from 2018-data. On June 4, 8 and 11, evening samples (18:00) were used as constraints rather than predawn samples (6:00), which resulted in smaller gaps between consecutive days (Fig. 7(c)). On days without sampling, VWC records were the averages of forward (dashed blue line) or backward (dashed orange line) reconstructions. One June 9 and 10, the weighted average based on the distance to the sampling date was considered the best estimate of VWC. 

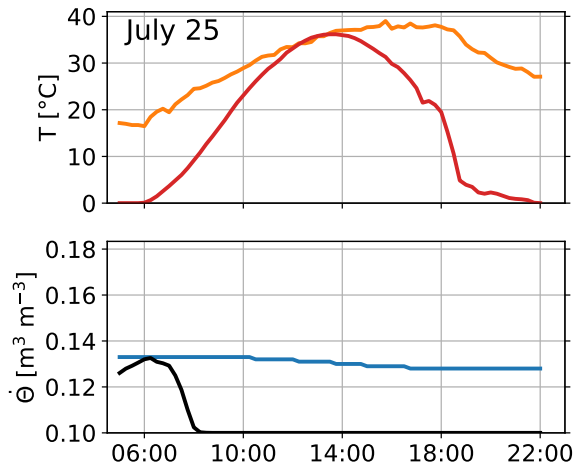
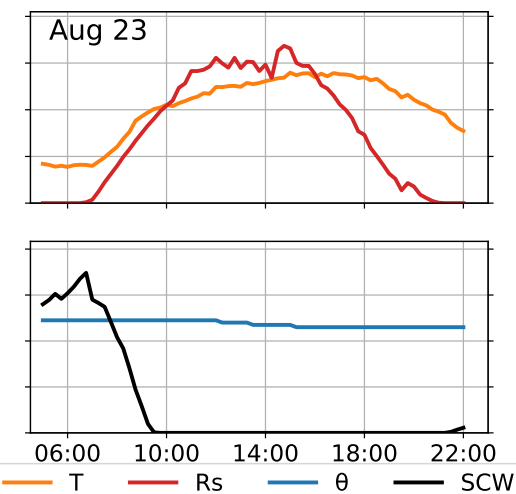
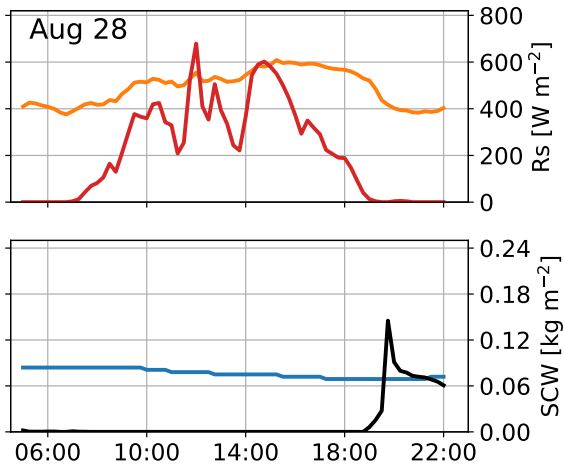

Figure 6. Environmental conditions on the sampling days July 25, August 23 and August 28 (2019). The upper row shows air temperature (T) and solar radiation (Rs), and the lower row shows root zone soil moisture ( $\theta$ ) and surface canopy water (SCW).

The diurnal VWC pattern on June 5 and 6 seems physically implausible, because one would not expect an enormous increase of VWC on the warmest and driest day (June 5), and a drop on the most rainy/cloudy day (June 6). This may be an artefact of applying CDF-matching when ET is very limited (e.g. June 6), and therefore markedly different to the rest of the period (see Fig. 4(d)).

\subsection{The effect on sub-daily L-band backscatter}

Fig. 8 illustrates the potential value of reconstructing VWC records for interpreting time series of microwave remote sensing data, in this case L-band backscatter. The upper three panels show the VV-, HH- and cross-polarized backscatter coefficients, respectively. Fig. 8(d) shows the sampled and reconstructed VWC, together with the total canopy water (CW), which is the sum of the reconstructed VWC and surface canopy water $\left[\mathrm{kg} \mathrm{m}^{-2}\right]$. The latter is either rainfall interception, characterized by rapid increases and often transient because of daytime evaporation, or dew formation, which accumulates gradually during the night and dissipates quickly after sunrise. Fig. $8(\mathrm{e})$ shows the volumetric soil moisture at $-5 \mathrm{~cm}$ depth.

Sub-daily variability of $>2 \mathrm{~dB}$ was found in all three polarizations. A sharp backscatter increase after rainfall was observed in all polarizations. Slow downward trends were also found corresponding with drydown in soil moisture. However, on a sub-daily time scale, backscatter variability shows strong similarities with diurnal patterns of canopy water (d). These diurnal cycles are most clearly visible in VV-pol. In fact, when randomly occurring rain events are excluded, the sub-daily backscatter behaviour can be analyzed using three distinct sub-daily periods: (1) from midnight to early morning, (2) from early morning to afternoon, (3) from afternoon to midnight. The aggregated data in Fig. 9 help to visualize the dynamics in these periods. Because rain fell more often in the afternoon and evening, the exclusion of periods with rainfall led to data aggregation across 9, 6 and 4 days in these three periods, respectively. Around midnight, dew started to form until its peak between 7:00 and 7:30, which is within an hour after sunrise around 6:30. In this same period, VWC was stable and surface soil moisture decreased slightly. VV and cross-polarized backscatter increased, following dew formation, while HH-polarized stayed relatively stable. 
(a)

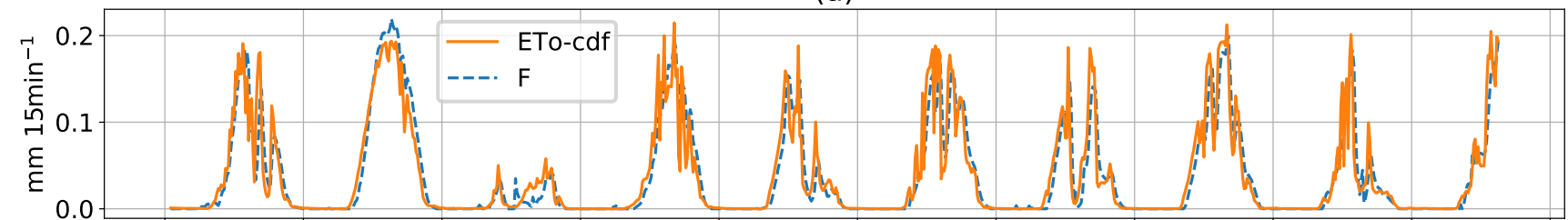

(b)
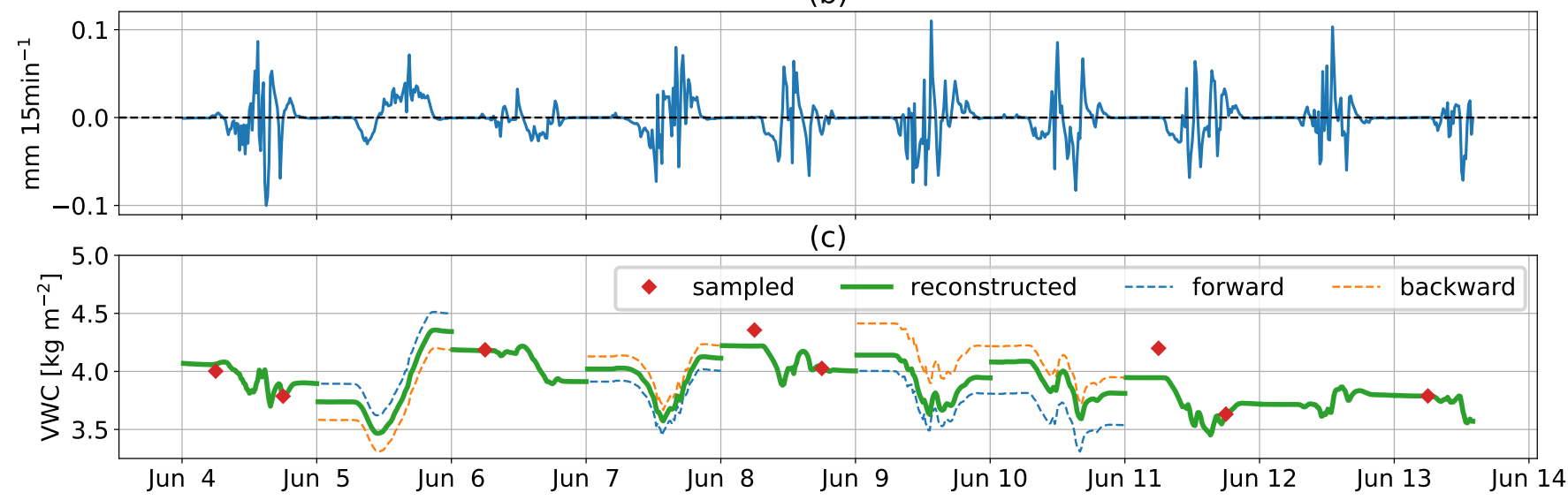

Figure 7. 10-day reconstruction of VWC, with (a) sap flow (F), and estimated transpiration (ETo-cdf), (b) the difference between sap flow and transpiration, and (c) the sampled and reconstructed VWC. In between sampling days, VWC estimates are the weighted average between forward and backward reconstructions from the consecutive sampling days (based on the time to the closest sampling day).

From early morning (7:30) to afternoon (14:00), dew dissipated and VWC dropped significantly. The same holds for backscatter in all polarizations, while surface soil moisture was still relatively stable. Finally, the last period of the day is characterized by refilling of the plant's internal water storage, and a decrease of soil moisture. The fact that backscatter in all polarizations remain relatively constant at first illustrates the the counterbalancing effects of soil moisture and VWC on backscatter in this period. During the last four aggregated acquisitions, VV- and cross-polarized backscatter show an increasing trend similar to VWC.

The separate effects of the different moisture stores on backscatter $\left(\sigma^{0}\right)$ were quantified through multiple linear regression. Because we considered the VWC reconstructions from June 5 and 6 as less reliable, the period between June 7 and 13 was used for the regression. Table 1 presents the estimated regression coefficients found for this period (see equation 3). These coefficients show that from all polarizations, VV-pol was most sensitive to internal vegetation water storage, and least sensitive to soil moisture. Compared to other polarizations, HH-pol was least sensitive to VWC and SCW, and most sensitive to soil moisture. Cross-pol was more sensitive to SCW than co-pol. Note that the coefficients from soil and vegetation water stores (Table 1) have non-homogeneous physical units. However, these coefficients tell us that on a typical dry day, a soil moisture content reduction of $0.02 \mathrm{~m}^{3} \mathrm{~m}^{-3}$ decreases $\mathrm{VV}, \mathrm{HH}$ and cross-polarized backscatter with $-0.5,-0.8$ and $-0.8 \mathrm{~dB}$, respectively. 
(a)

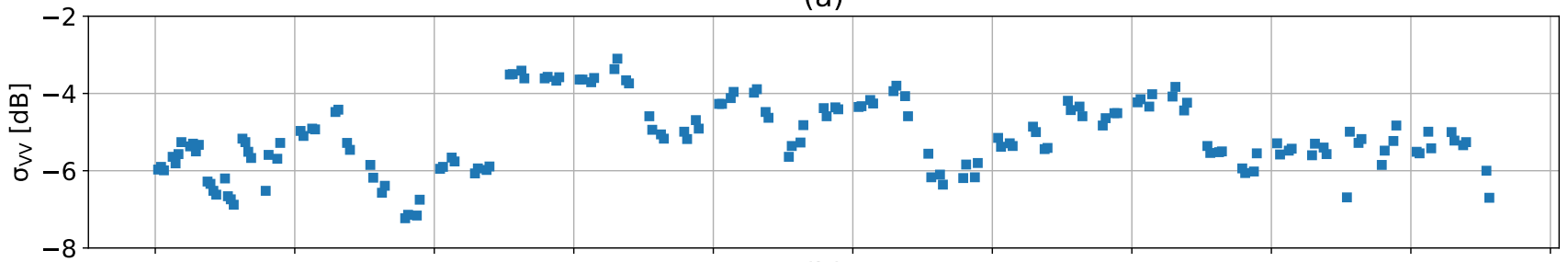

(b)

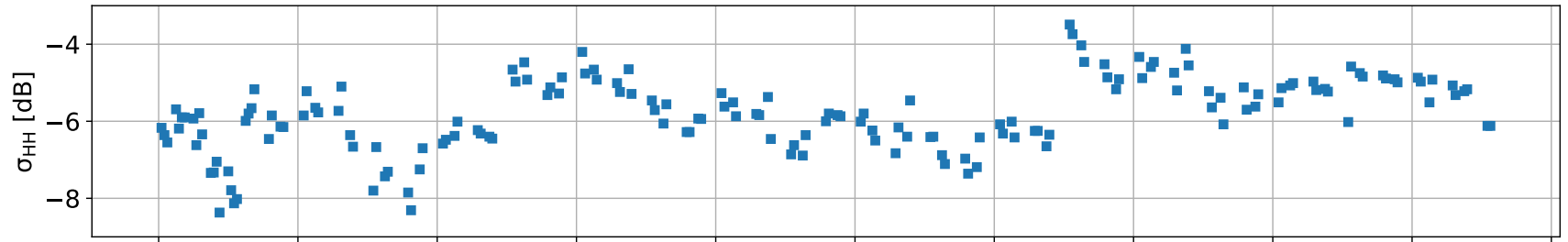

(c)

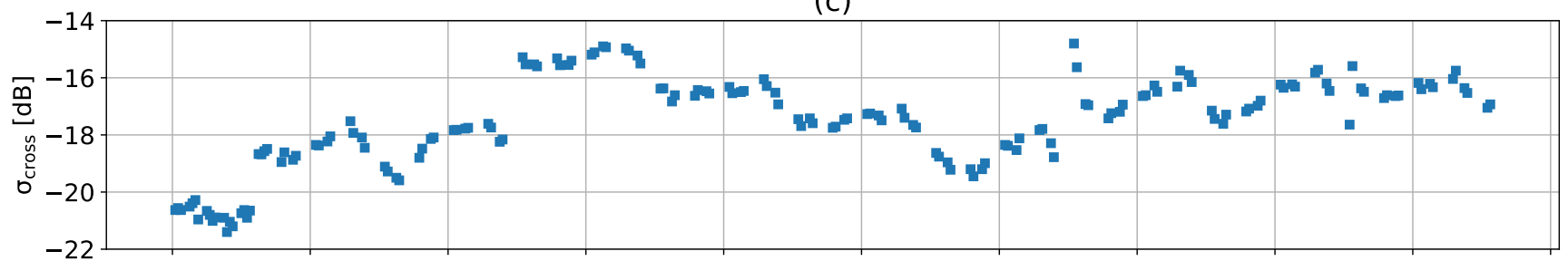

(d)

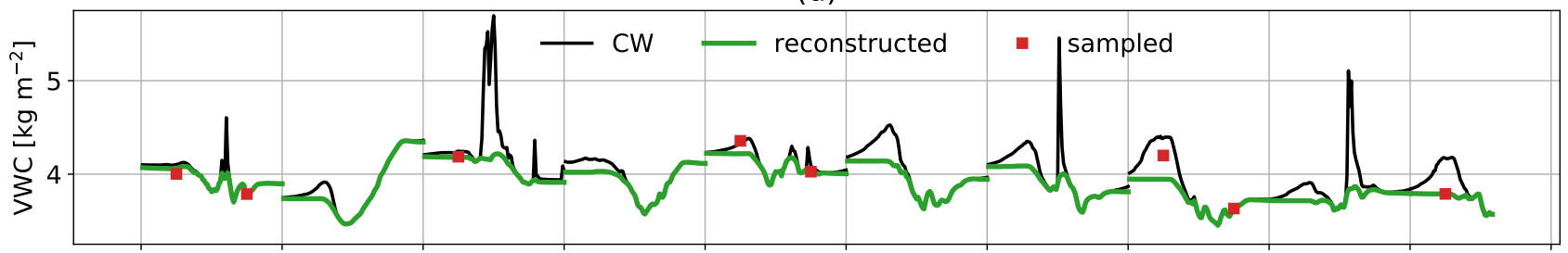

(e)

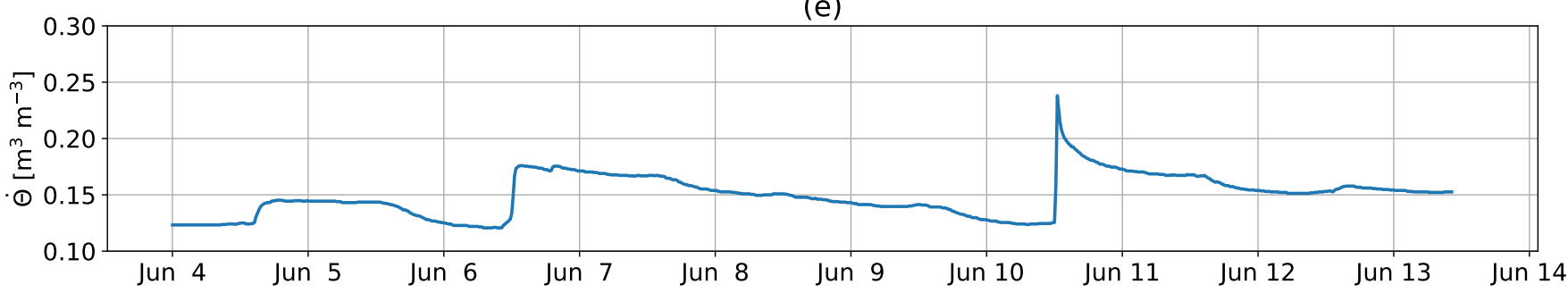

Figure 8. Full polarimetric L-band backscatter and separated effects for a 10-day period near the end of the growing season in 2018, with (a) VV-polarized scattering coefficient, (b) HH-polarized scattering coefficient, and (c) averaged VH and HV-polarized scattering coefficients, (d) sampled and reconstructed VWC, and total canopy water, which is the sum of reconstructed VWC and SCW, and (e) soil moisture at 5 cm depth.

Similarly, a typical VWC cycle amplitude of $0.5 \mathrm{~kg} \mathrm{~m}^{-2}$ affects $\sigma^{0}$ with $1.5 \mathrm{~dB}(\mathrm{VV}), 1.1 \mathrm{~dB}(\mathrm{HH})$, and $1.2 \mathrm{~dB}$ (cross). That means that the diurnal variation in VV-pol is three times more sensitive to variations in VWC than soil moisture on a typical 
(a) Midnight-morning

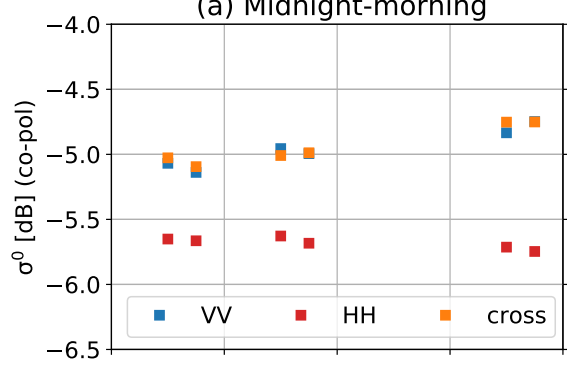

(d) Midnight-morning

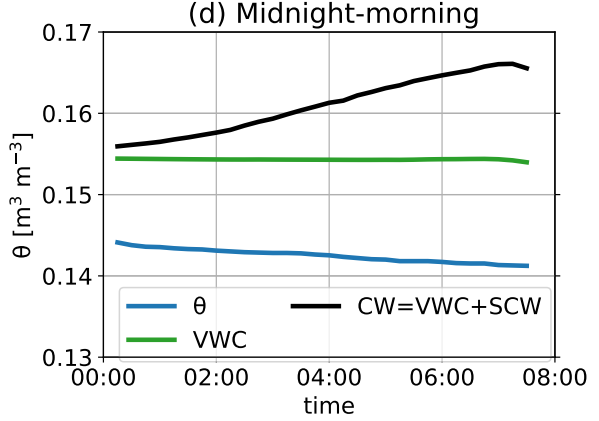

Backscatter

(b) Morning-afternoon

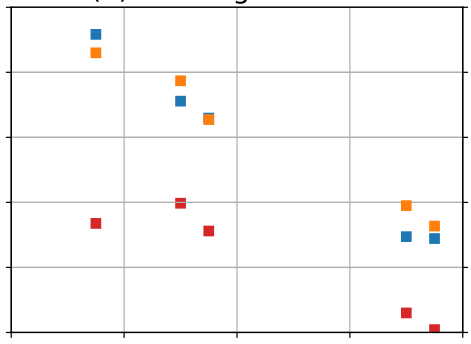

Moisture stores

(e) Morning-afternoon

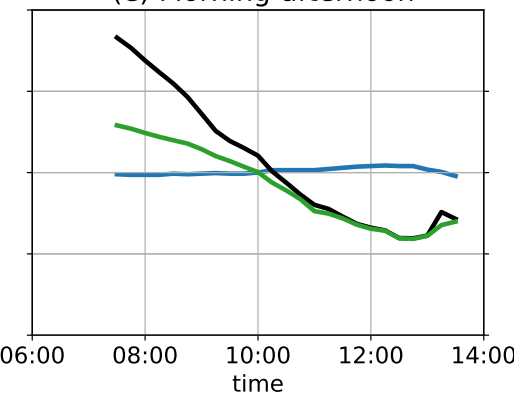

(c) Afternoon-evening

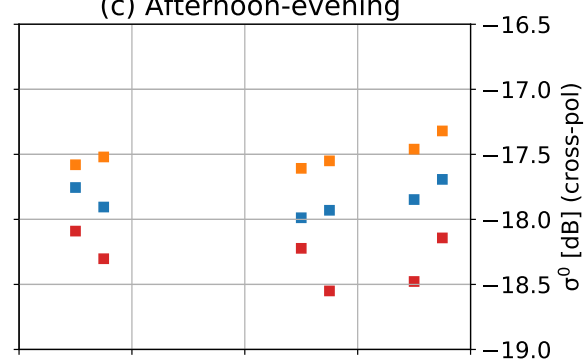

(f) Afternoon-evening

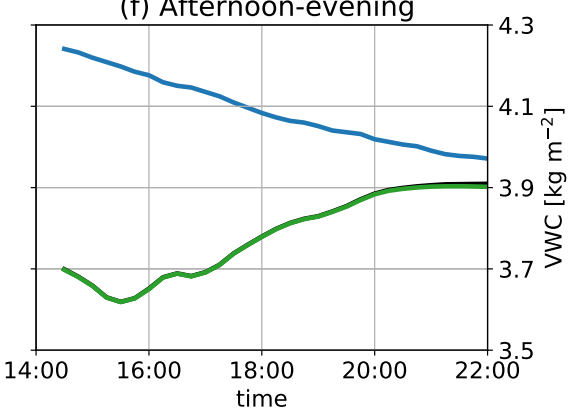

Figure 9. Backscatter (VV, HH, cross-pol) and moisture (VWC, CW, $\theta$ ) data aggregated across multiple days, and separated by part of the day: midnight-morning, morning-afternoon, and afternoon-midnight. Periods with disturbing rain events are excluded, which means that data in (a,d), (b,e), and (c,f) are aggregated across 9, 6 and 4 days, respectively. Canopy Water (CW) is SCW displayed on top of VWC.

dry day. On the same day, diurnal variations in HH- and cross-polarized backscatter are 1.5 times more sensitive to the VWC cycle than soil moisture drydown. Dew formation and dissipation of $0.3 \mathrm{~kg} \mathrm{~m}^{-2}$ causes $\sigma^{0}$ to vary with $0.2,0.1$ and $0.2 \mathrm{~dB}$, respectively. However, note from Fig. 10 that particularly the effect of SCW on backscatter is still underestimated.

Table 1. Estimated regression coefficients per polarization for the period June 7-13, 2018 (equation 3).

\begin{tabular}{llll}
\hline & VV-pol & HH-pol & Cross-pol \\
\hline$a\left[d B / \mathrm{m}^{3} \mathrm{~m}^{-3}\right]$ & 24.06 & 39.47 & 38.83 \\
$b\left[\mathrm{~dB} / \mathrm{kgm}^{-2}\right]$ & 2.93 & 2.29 & 2.45 \\
$c\left[\mathrm{~dB} / \mathrm{kgm}^{-2}\right]$ & 0.62 & 0.38 & 0.73 \\
\hline
\end{tabular}


(a) VV

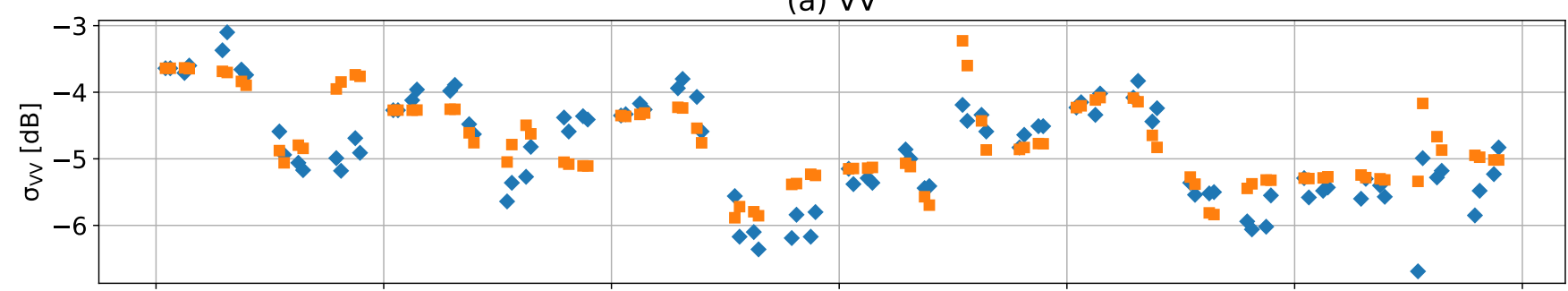

(b) $\mathrm{HH}$

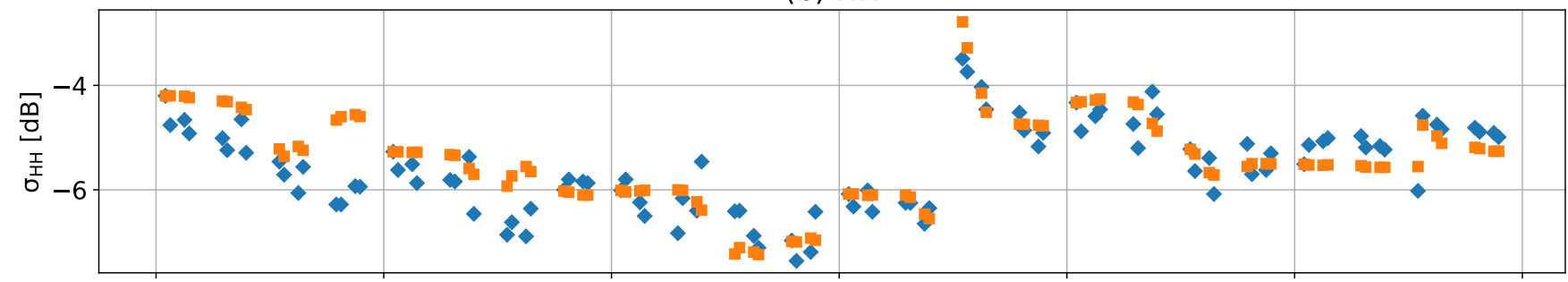

(c) Cross-pol

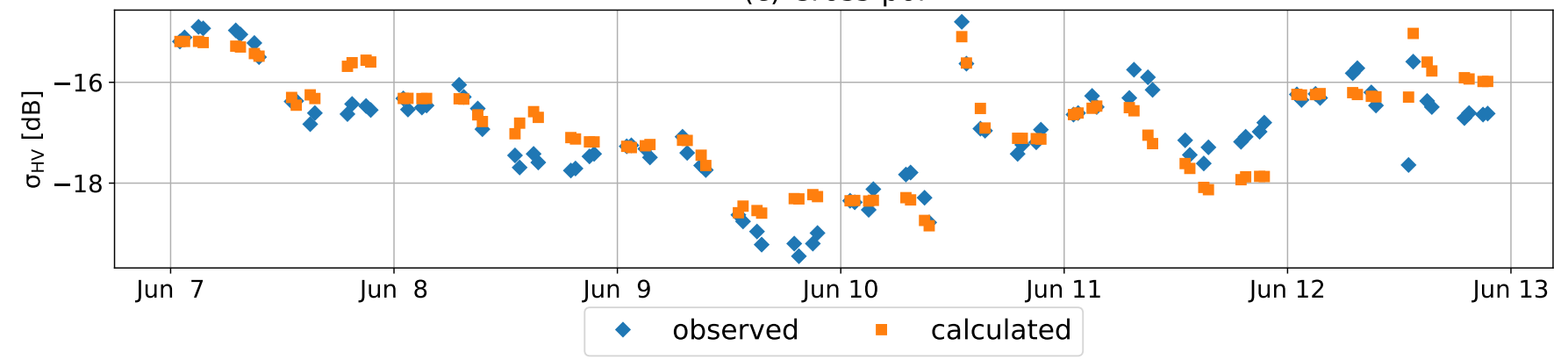

Figure 10. Observed and calculated (a) VV-, (b) HH-, and (c) cross-polarized $\sigma^{0}$ from June 7-13, 2018.

\section{Discussion}

\subsection{Sub-daily Vegetation Water Content estimates: observations and reconstructions}

Our results showed that in non-stressed conditions, VWC depleted by 10-20\% during the day. This internal VWC withdrawal is approximately $10-20 \%$ of total daily transpiration, which is similar to findings from tropical and temperate broad-leaved trees (Meinzer et al. (2004); Köcher et al. (2013)). In stressed conditions, we found a 35\% drop of VWC during the day.

Our reconstruction results confirm that it is possible to estimate 15-min changes in corn VWC with only sap flow sensors, a weather station and occasional destructive samples. In general, we found the best agreement between reconstructed and sampled VWC when the daily cycle of transpiration was estimated from multi-day sap flow observations and ETo estimates. Moreover, the application of CDF-matching improved the reconstruction substantially on July 25, while on August 28, a good agreement was already found after linear correction (Fig. 5). This difference could partly be explained by the suppressing effect of dew, observed on July 25 (Fig. 6), has on transpiration (Dawson and Goldsmith (2018)), which is not captured by 
ETo (Langensiepen et al. (2009)). When ETo rates are low, estimated transpiration is lower after CDF-matching than after linear correction (see Fig. 4(d)). Consequently, CDF-matching mimicked the suppressing effect of dew due to the reduction in transpiration rates in the morning. When we look at the period between the peak of dew (06:00) and full dissipation (08:15) on July 25 in Fig. 5, we see that $\Delta \mathrm{VWC}$ is $0.17 \mathrm{~kg} \mathrm{~m}^{-2}$ in the second row, while $\Delta \mathrm{VWC}$ is $0.1 \mathrm{~kg} \mathrm{~m}^{-2}$ in the third row. This means that CDF-matching in this case led to reduction of transpiration of $0.07 \mathrm{~kg} \mathrm{~m}^{-2}$. This is comparable to estimated dew evaporation in this period, which was $0.09 \mathrm{~kg} \mathrm{~m}^{-2}$. The same holds for August 23, when we found a transpiration reduction of about $0.18 \mathrm{~kg} \mathrm{~m}^{-2}$ between 6:45 and 09:45 after CDF-matching and an estimated dew evaporation of $0.20 \mathrm{~kg} \mathrm{~m}^{-2}$ in the same period. On August 28, all dew had already dissipated before sunrise and did thus not affect transpiration. Therefore, a reduction of transpiration rates did not improve the reconstruction of VWC. These results illustrate that the suppressing effect of dew on transpiration should be taken into account when one estimates transpiration with a weather station or flux tower.

Another effect of CDF-matching was that the highest ETo rates resulted in higher estimates of transpiration compared to those obtained using linear corrections (see Fig. 4(d)). This was particularly apparent under sunny conditions such as on July 25 and August 23. This means that transpiration rates exceeded sap flow rates for a longer period. Together with the gradual depletion of internal VWC in the morning, this led to a much better agreement, and a shift of a diurnal minimum towards the afternoon. However, the poor agreement between sampled and reconstructed VWC in the evening of August 23 could not be explained by extreme hydrometeorological conditions, growth stage or drought stress. Other potential contributors to the poor agreement could be unaccounted for errors in the sap flow, weather data or samples. The cloudier conditions on August 28 (Fig. 6) could explain the small difference between linear corrections and CDF-matching.

The observed period in 2018 was characterized by daily dew formation and high temperatures, which could explain why the diurnal minima of reconstructed VWC, obtained through the CDF-matching approach, matched excellently with the diurnal minima in the backscatter in most cases (Fig. 8). However, discontinuities were observed between consecutive days (Fig. 7), which might be related to the temporal resolution of the observations and the estimation of transpiration fluxes. The temporal resolution of the sensor observations was 15 minutes. At the same time, we found phase differences between ETo and sap flow in the order of 15-45 min, which was consistent with previous studies on corn (e.g. Langensiepen et al. (2009)). Increasing the ratio between phase difference and observation resolution would increase the robustness of the method. A potential solution would therefore be to increase the temporal resolution of the sensor observations. Another potential solution is related to the estimation of transpiration fluxes. Ideally, a flux tower would be used for ET estimates through the eddy covariance method, as it is a more direct measurement and widely considered as the most accurate technique for ET measurements at field scale (Zhang et al. (2014); Maltese et al. (2018); Oguntunde et al. (2004)). Improved ET estimates may also reduce or eliminate the need to include CDF-matching. As direct ET measurements also include evaporation from SCW and soil, it is advised to include leaf wetness sensors and micro-lysimeters (Ding et al. (2013)) to provide quantitative estimates of evaporation and determine transpiration from ET measurements. Including several in situ sensors of each type (e.g. leaf wetness, sap flow etc.) ensures that the quantities capture field-scale dynamics. 


\subsection{Interpreting sub-daily backscatter}

In Vermunt et al. (2021), sub-daily L-band backscatter variations were attributed to VWC, SCW and soil moisture. However, the lack of sub-daily VWC data points complicated quantifying the relation between backscatter and the individual moisture stores. The VWC records generated in the current study allowed us to understand sub-daily backscatter variations with unprecedented detail, and to describe the relative backscatter sensitivity to the different moisture stores.

The results presented here confirm that the effects of sub-daily variations in VWC on backscatter are significant. For our 10-day time series we found that, on typical dry days, variations in backscatter were 1.5 (HH- and cross-pol) to 3 (VV-pol) times more sensitive to the diurnal cycle of VWC than to soil moisture variations. Note that these ratios can be different when either VWC or soil moisture content substantially change (Brisco et al. (1990)), or when crop structure changes during the day Kimes and Kirchner (1983). Backscatter sensitivity to VWC dynamics were most clearly observed in the period between sunrise and mid-afternoon, when both dropped significantly. During mid-afternoon to sunset, refilling of VWC and drop in soil moisture had opposite effects on backscatter, which led to constant to slightly increasing VV- and cross-polarized backscatter. Nocturnal backscatter dynamics demonstrated the sensitivity of VV- and cross-pol to SCW.

In general, our results showed that VV-pol was more sensitive to variations in VWC than HH-pol, and less sensitive to variations in soil moisture. This is in agreement with Joseph et al. (2010), who described a larger attenuation of the soil return by vegetation for VV-pol compared to HH-pol in a study on the L-band backscattering of corn. An explanation for this difference was given by Stamenković et al. (2015), who described that at VV and HV polarizations, vertical corn stems attenuate the double-bounce scattering at L-band, which results in lower contribution from the soil. As a consequence, volume scattering and the corresponding contribution from vegetation becomes dominant. At $\mathrm{HH}-$ pol, there is less attenuation of the double bounce effect, which explains a higher sensitivity to soil moisture.

Moreover, nocturnal VV- and cross-polarizated backscatter increase could be assigned to dew formation only, because VWC was stable during the night and soil moisture was constant or slightly decreased. Stable nocturnal VWC can be expected for crops with a hydraulic capacitance similar to or lower than corn, and sufficient soil moisture availability. For vegetation with a larger hydraulic capacitance or low soil moisture availability, nocturnal refilling of VWC could be expected (Maltese et al. (2018)), which could complicate the separation of signals from VWC and SCW.

Our time series showed that, compared to HH-pol, VV- and cross-polarized backscatter were not only more sensitive to changes in VWC, but also to changing SCW. This is in agreement with previous findings from Brancato et al. (2017), who found a stronger effect of SCW on S- and C-band differential interferometric observables in VV polarization compared to other polarizations, particularly for vertically oriented crops as corn. This could be related to increased scattering from wet leaves in combination with the dominance of volume scattering in VV and cross polarizations. The different sensitivities to VWC and SCW suggest that other scattering mechanisms are affected by the presence of SCW as well. Additional research is needed to provide more insight into these scattering mechanisms under the presence of SCW. 


\section{Conclusions}

The potential of using radar for (eco)hydrological studies is limited by the challenge to separate signals from soil and vegetation on a sub-daily timescale. To gain better understanding of what controls sub-daily backscatter behaviour, we analyzed towerbased polarimetric L-band observations from a corn field using unique estimates of moisture fluctuations in vegetation and soil.

A method developed by the tree physiology community was adapted to estimate continuous variations in corn plant water content with unprecedented detail. The adaptations were related to the estimation of transpiration. The best agreement between sampled and estimated VWC was found when transpiration estimates were obtained after the removal of systematic differences between ETo and sap flow. In non-stressed conditions, predawn VWC decreased by 10-20\% during the day.

Complementing the resulting record of VWC with records of soil moisture and previously estimated surface canopy water allowed us to interpret the sub-daily behaviour of polarimetric L-band observations. The results showed a significant effect of diurnal VWC cycles on L-band backscatter when the plants reached their maximum size. The highest and lowest sensitivity to VWC was found in VV- and HH-polarized backscatter, respectively. The backscatter behaviour on typical dry days was 1.5 (HH, cross-pol) to 3 (VV) times more determined by the VWC cycle than by soil moisture. Nighttime increases in VV- and cross-polarized backscatter were a result of dew formation only.

The results presented here provide unique insight into the potentially confounding influence of surface and internal vegetation water content variations on backscatter, particularly in the interpretation of sub-daily radar observations. These findings are directly relevant for current and upcoming L-band missions, but also for the design of future spaceborne SAR missions for land applications. In particular, this study highlights the potential difference in relative importance of VWC, SCW or soil moisture dynamics depending on the overpass time. This is particularly relevant given the imminent availability of sub-daily observations from e.g. the Iceye and CapellaSpace constellations. Moreover, the method for reconstructing VWC from sparse ground data has huge potential for validating and interpreting a wide range of other remotely sensing techniques that are sensitive to vegetation water, such as passive microwave remote sensing, Global Navigation Satellite Systems (GNSS) and Cosmic Ray Neutron Sensors. 


\section{Appendix A}

Table A1. Root mean squared error (RMSE) between reconstructed and sampled VWC. The rows represent time of constraining the reconstruction, while the columns represent the considered period for linear ETo correction

\begin{tabular}{|c|c|c|c|c|c|c|c|c|c|c|c|c|c|}
\hline & \multicolumn{3}{|c|}{ July 25} & \multicolumn{5}{|c|}{ August 23} & \multicolumn{5}{|c|}{ August 28} \\
\hline & 1 day & 3 days & all data & 1 day & 3 days & 5 days & 7 days & all data & 1 day & 3 days & 5 days & 7 days & all data \\
\hline predawn & 0.212 & 0.272 & 1.107 & 0.369 & 0.310 & 0.256 & 0.282 & 0.547 & 0.178 & 0.097 & 0.095 & 0.063 & 0.352 \\
\hline morning & 0.314 & 0.369 & 1.082 & 0.500 & 0.444 & 0.389 & 0.416 & 0.655 & 0.176 & 0.110 & 0.108 & 0.078 & 0.315 \\
\hline afternoon & 0.187 & 0.220 & 0.704 & 0.375 & 0.346 & 0.318 & 0.331 & 0.468 & 0.129 & 0.090 & 0.089 & 0.075 & 0.227 \\
\hline evening & 0.266 & 0.321 & 1.036 & 0.446 & 0.392 & 0.337 & 0.364 & 0.601 & 0.206 & 0.138 & 0.136 & 0.106 & 0.351 \\
\hline sunset & 0.247 & 0.311 & 1.131 & 0.516 & 0.448 & 0.379 & 0.413 & 0.706 & 0.150 & 0.074 & 0.072 & 0.047 & 0.317 \\
\hline
\end{tabular}

Table A2. Root mean squared error (RMSE) between reconstructed and sampled VWC. The rows represent time of constraining the reconstruction, while the columns represent the considered period for CDF-matching

\begin{tabular}{|c|c|c|c|c|c|c|c|c|c|c|c|c|c|}
\hline & \multicolumn{3}{|c|}{ July 25} & \multicolumn{5}{|c|}{ August 23} & \multicolumn{5}{|c|}{ August 28} \\
\hline & 1 day & 3 days & all data & 1 day & 3 days & 5 days & 7 days & all data & 1 day & 3 days & 5 days & 7 days & all data \\
\hline predawn & 0.155 & 0.140 & 0.070 & 0.303 & 0.380 & 0.295 & 0.310 & 0.458 & 0.135 & 0.112 & 0.153 & 0.149 & 0.379 \\
\hline morning & 0.114 & 0.104 & 0.124 & 0.296 & 0.390 & 0.313 & 0.331 & 0.508 & 0.121 & 0.078 & 0.100 & 0.088 & 0.286 \\
\hline afternoon & 0.140 & 0.136 & 0.125 & 0.309 & 0.351 & 0.311 & 0.319 & 0.402 & 0.091 & 0.060 & 0.075 & 0.067 & 0.212 \\
\hline evening & 0.094 & 0.081 & 0.113 & 0.244 & 0.333 & 0.259 & 0.276 & 0.451 & 0.142 & 0.084 & 0.103 & 0.083 & 0.306 \\
\hline sunset & 0.177 & 0.162 & 0.083 & 0.471 & 0.548 & 0.460 & 0.474 & 0.623 & 0.102 & 0.070 & 0.106 & 0.097 & 0.325 \\
\hline
\end{tabular}

Table A3. Offset between reconstructed and sampled VWC. The rows represent the method used for transpiration estimation, while the columns represent the considered period.

\begin{tabular}{|c|c|c|c|c|c|c|c|c|c|c|c|c|c|}
\hline & \multicolumn{4}{|c|}{ June 4} & \multicolumn{5}{|c|}{ June 8} & \multicolumn{4}{|c|}{ June 11} \\
\hline & 1 day & 3 days & 5 days & all data & 1 day & 3 days & 5 days & 7 days & all data & 1 day & 3 days & 5 days & all data \\
\hline linear & 0.202 & 0.250 & 0.149 & 0.055 & 0.412 & 0.071 & 0.241 & 0.022 & 0.022 & 0.556 & 0.790 & 0.739 & 0.543 \\
\hline cdf & 0.134 & 0.180 & 0.185 & 0.063 & 0.292 & 0.106 & 0.209 & 0.147 & 0.128 & 0.456 & 0.476 & 0.521 & 0.267 \\
\hline
\end{tabular}


https://doi.org/10.5194/hess-2021-459

Preprint. Discussion started: 17 September 2021

(c) Author(s) 2021. CC BY 4.0 License.

Author contributions. PV, SSD and NvdG were responsible for the conceptualization, methodology, formal analysis, investigation, visualization and writing (original draft preparation). JJ provided resources (scatterometer data). PV and SK conducted the ground-measurements.

405 SSD and NvdG provided supervision. All authors contributed to writing (review and editing).

Competing interests. The authors declare that they have no conflict of interest.

Acknowledgements. This project was supported by Vidi Grant 14126 from the Dutch Technology Foundation STW, which is part of The Netherlands Organisation for Scientific Research (NWO), and which is partly funded by the Ministry of Economic Affairs. The experiment in 2018 was made possible by infrastructural and technical support from the Agr. and Biol. Eng. Dept. and PSREU at the University of

410 Florida. The authors wish to acknowledge the help from Daniel Preston, Patrick Rush, Eduardo Carrascal, and James Boyer and his team in particular. The experiment in 2019 was made possible by infrastructural and technical support from Jacob van den Borne, Paul van Zoggel and their team. Vineet Kumar participated in the collection of field data in 2019. 


\section{References}

Allen, R. G., Pereira, L. S., Raes, D., and Smith, M.: Crop evapotranspiration: guidelines for computing crop water requirements, FAO Drainage and Irrigation Paper 56, Tech. rep., FAO - Food and Agriculture Organization of the United Nations, Rome, 1998.

Bartholomeus, R., de Louw, P., Witte, F., van Dam, J., van Deijl, D., Hoefsloot, P., van Huijgevoort, M., Hunink, J., America, I., Pouwels, J., and de Wit, J.: Droogte in zandgebieden van Zuid-, Midden-en Oost-Nederland: Het verhaal: analyse van droogte 2018 en 2019 en tussentijdse bevindingen., Tech. rep., KWR, https://edepot.wur.nl/534198, 2020.

Bracaglia, M., Ferrazzoli, P., and Guerriero, L.: A fully polarimetric multiple scattering model for crops, Remote Sensing of Environment, 54, 170-179, https://doi.org/10.1016/0034-4257(95)00151-4, 1995.

Brancato, V., Liebisch, F., and Hajnsek, I.: Impact of Plant Surface Moisture on Differential Interferometric Observables: A Controlled Electromagnetic Experiment, IEEE Transactions on Geoscience and Remote Sensing, 55, 3949-3964, https://doi.org/10.1109/TGRS.2017.2684814, 2017.

Brisco, B., Brown, R. J., Koehler, J. A., Sofko, G. J., and McKibben, M. J.: The diurnal pattern of microwave backscattering by wheat, Remote Sensing of Environment, 34, 37-47, https://doi.org/10.1016/0034-4257(90)90082-W, 1990.

Brocca, L., Hasenauer, S., Lacava, T., Melone, F., Moramarco, T., Wagner, W., Dorigo, W., Matgen, P., Martínez-Fernández, J., Llorens, P., Latron, J., Martin, C., and Bittelli, M.: Soil moisture estimation through ASCAT and AMSR-E sensors: An intercomparison and validation study across Europe, Remote Sensing of Environment, 115, 3390-3408, https://doi.org/10.1016/j.rse.2011.08.003, 2011.

Cosh, M. H., Kabela, E. D., Hornbuckle, B., Gleason, M. L., Jackson, T. J., and Prueger, J. H.: Observations of dew amount using in situ and satellite measurements in an agricultural landscape, Agricultural and Forest Meteorology, 149, 1082-1086, https://doi.org/10.1016/j.agrformet.2009.01.004, 2009.

Cosh, M. H., Ochsner, T. E., McKee, L., Dong, J., Basara, J. B., Evett, S. R., Hatch, C. E., Small, E. E., Steele-Dunne, S. C., Zreda, M., and Sayde, C.: The Soil Moisture Active Passive Marena, Oklahoma, In Situ Sensor Testbed (SMAP-MOISST): Testbed Design and Evaluation of In Situ Sensors, Vadose Zone Journal, 15, 1-11, https://doi.org/10.2136/vzj2015.09.0122, 2016.

Dawson, T. E. and Goldsmith, G. R.: The value of wet leaves, New Phytologist, 219, 1156-1169, https://doi.org/https://doi.org/10.1111/nph.15307, 2018.

Ding, R., Kang, S., Zhang, Y., Hao, X., Tong, L., and Du, T.: Partitioning evapotranspiration into soil evaporation and transpiration using a modified dual crop coefficient model in irrigated maize field with ground-mulching, Agricultural Water Management, 127, 85-96, https://doi.org/10.1016/j.agwat.2013.05.018, 2013.

Dobriyal, P., Qureshi, A., Badola, R., and Hussain, S. A.: A review of the methods available for estimating soil moisture and its implications for water resource management, Journal of Hydrology, 458-459, 110-117, https://doi.org/10.1016/j.jhydrol.2012.06.021, 2012.

Drusch, M., Wood, E. F., and Gao, H.: Observation operators for the direct assimilation of TRMM microwave imager retrieved soil moisture, Geophysical Research Letters, 32, L15 403, https://doi.org/https://doi.org/10.1029/2005GL023623, 2005.

El Hajj, M., Baghdadi, N., Wigneron, J.-P., Zribi, M., Albergel, C., Calvet, J.-C., and Fayad, I.: First Vegetation Optical Depth Mapping from Sentinel-1 C-band SAR Data over Crop Fields, Remote Sensing, 11, 2769, https://doi.org/10.3390/rs11232769, 2019.

Emmerik, T. v., Steele-Dunne, S. C., Judge, J., and Giesen, N. v. d.: Impact of Diurnal Variation in Vegetation Water Content on Radar Backscatter From Maize During Water Stress, IEEE Transactions on Geoscience and Remote Sensing, 53, 3855-3869, https://doi.org/10.1109/TGRS.2014.2386142, 2015. 
Emmerik, T. v., Steele-Dunne, S., Paget, A., Oliveira, R. S., Bittencourt, P. R. L., Barros, F. d. V., and Giesen, N. v. d.: Water stress detection in the Amazon using radar, Geophysical Research Letters, 44, 6841-6849, https://doi.org/10.1002/2017GL073747, 2017.

Entekhabi, D., Njoku, E. G., O’Neill, P. E., Kellogg, K. H., Crow, W. T., Edelstein, W. N., Entin, J. K., Goodman, S. D., Jackson, T. J., Johnson, J., Kimball, J., Piepmeier, J. R., Koster, R. D., Martin, N., McDonald, K. C., Moghaddam, M., Moran, S., Reichle, R., Shi, J. C., Spencer, M. W., Thurman, S. W., Tsang, L., and Zyl, J. V.: The Soil Moisture Active Passive (SMAP) Mission, Proceedings of the IEEE, 98, 704-716, https://doi.org/10.1109/JPROC.2010.2043918, 2010.

Farquharson, G., Castelletti, D., Stringham, C., and Eddy, D.: An Update on the Capella Space Radar Constellation, in: EUSAR 2021; 13th European Conference on Synthetic Aperture Radar, pp. 1-4, Online, 2021.

Frolking, S., Milliman, T., Palace, M., Wisser, D., Lammers, R., and Fahnestock, M.: Tropical forest backscatter anomaly evident in SeaWinds scatterometer morning overpass data during 2005 drought in Amazonia, Remote Sensing of Environment, 115, 897-907, https://doi.org/10.1016/j.rse.2010.11.017, 2011.

Goldstein, G., Andrade, J. L., Meinzer, F. C., Holbrook, N. M., Cavelier, J., Jackson, P., and Celis, A.: Stem water storage and diurnal patterns of water use in tropical forest canopy trees, Plant, Cell \& Environment, 21, 397-406, https://doi.org/https://doi.org/10.1046/j.13653040.1998.00273.x, 1998.

Hamadi, A., Albinet, C., Borderies, P., Koleck, T., Villard, L., Ho Tong Minh, D., and Le Toan, T.: Temporal Survey of Polarimetric P-Band Scattering of Tropical Forests, IEEE Transactions on Geoscience and Remote Sensing, 52, 4539 - 4547, https://doi.org/10.1109/TGRS.2013.2282357, 2014.

Ignatenko, V., Laurila, P., Radius, A., Lamentowski, L., Antropov, O., and Muff, D.: ICEYE Microsatellite SAR Constellation Status Update: Evaluation of First Commercial Imaging Modes, pp. 3581-3584, IGARSS - IEEE International Geoscience and Remote Sensing Symposium, Online, https://doi.org/10.1109/IGARSS39084.2020.9324531, 2020.

Joseph, A. T., van der Velde, R., O’Neill, P. E., Lang, R., and Gish, T.: Effects of corn on C- and L-band radar backscatter: A correction method for soil moisture retrieval, Remote Sensing of Environment, 114, 2417-2430, https://doi.org/10.1016/j.rse.2010.05.017, 2010.

Kim, S.-B., Zyl, J. J. v., Johnson, J. T., Moghaddam, M., Tsang, L., Colliander, A., Dunbar, R. S., Jackson, T. J., Jaruwatanadilok, S., West, R., Berg, A., Caldwell, T., Cosh, M. H., Goodrich, D. C., Livingston, S., López-Baeza, E., Rowlandson, T., Thibeault, M., Walker, J. P., Entekhabi, D., Njoku, E. G., O’Neill, P. E., and Yueh, S. H.: Surface Soil Moisture Retrieval Using the L-Band Synthetic Aperture Radar Onboard the Soil Moisture Active-Passive Satellite and Evaluation at Core Validation Sites, IEEE Transactions on Geoscience and Remote Sensing, 55, 1897-1914, https://doi.org/10.1109/TGRS.2016.2631126, 2017.

Kimes, D. S. and Kirchner, J. A.: Diurnal variations of vegetation canopy structure, International Journal of Remote Sensing, 4, 257-271, https://doi.org/10.1080/01431168308948545, 1983.

Konings, A. G., Yu, Y., Xu, L., Yang, Y., Schimel, D. S., and Saatchi, S. S.: Active microwave observations of diurnal and seasonal variations of canopy water content across the humid African tropical forests, Geophysical Research Letters, 44, 2290-2299, https://doi.org/10.1002/2016GL072388, 2017.

Konings, A. G., Rao, K., and Steele-Dunne, S. C.: Macro to micro: microwave remote sensing of plant water content for physiology and ecology, New Phytologist, 223, 1166-1172, https://doi.org/https://doi.org/10.1111/nph.15808, 2019.

Köcher, P., Horna, V., and Leuschner, C.: Stem water storage in five coexisting temperate broad-leaved tree species: significance, temporal dynamics and dependence on tree functional traits, Tree Physiology, 33, 817-832, https://doi.org/10.1093/treephys/tpt055, 2013. 

T.: Quantifying the uncertainties of transpiration calculations with the Penman-Monteith equation under different climate and optimum water supply conditions, Agricultural and Forest Meteorology, 149, 1063-1072, https://doi.org/10.1016/j.agrformet.2009.01.001, 2009.

Maltese, A., Awada, H., Capodici, F., Ciraolo, G., La Loggia, G., and Rallo, G.: On the Use of the Eddy Covariance Latent Heat Flux and Sap Flow Transpiration for the Validation of a Surface Energy Balance Model, Remote Sensing, 10, 195, https://doi.org/10.3390/rs10020195, 2018.

Meinzer, F. C., James, S. A., and Goldstein, G.: Dynamics of transpiration, sap flow and use of stored water in tropical forest canopy trees, Tree Physiology, 24, 901-909, https://doi.org/10.1093/treephys/24.8.901, 2004.

Monteith, A. R. and Ulander, L. M. H.: Temporal Characteristics of P-Band Tomographic Radar Backscatter of a Boreal Forest, IEEE Journal of Selected Topics in Applied Earth Observations and Remote Sensing, 14, 1967-1984, https://doi.org/10.1109/JSTARS.2021.3050611, 2021.

Nagarajan, K., Liu, P., DeRoo, R., Judge, J., Akbar, R., Rush, P., Feagle, S., Preston, D., and Terwilleger, R.: Automated L-Band Radar System for Sensing Soil Moisture at High Temporal Resolution, IEEE Geoscience and Remote Sensing Letters, 11, 504-508, https://doi.org/10.1109/LGRS.2013.2270453, 2014.

Oguntunde, P. G., Giesen, N. C. v. d., Vlek, P. L. G., and Eggers, H.: Water Flux in a Cashew Orchard during a Wet-to-Dry Transition Period: Analysis of Sap Flow and Eddy Correlation Measurements, Earth Interactions, 8, 1-17, https://doi.org/10.1175/10873562(2004)8<1:WFIACO >2.0.CO;2, 2004.

Paget, A. C., Long, D. G., and Madsen, N. M.: RapidScat Diurnal Cycles Over Land, IEEE Transactions on Geoscience and Remote Sensing, 54, 3336-3344, https://doi.org/10.1109/TGRS.2016.2515022, 2016.

Phillips, N. G., Scholz, F. G., Bucci, S. J., Goldstein, G., and Meinzer, F. C.: Using branch and basal trunk sap flow measurements to estimate whole-plant water capacitance: comment on Burgess and Dawson (2008), Plant and Soil, 315, 315-324, https://doi.org/10.1007/s11104008-9741-y, 2008.

Pierdicca, N., Davidson, M., Chini, M., Dierking, W., Djavidnia, S., Haarpaintner, J., Hajduch, G., Laurin, G. V., Lavalle, M., LópezMartínez, C., Nagler, T., and Su, B.: The Copernicus L-band SAR mission ROSE-L (Radar Observing System for Europe) (Conference Presentation), in: Active and Passive Microwave Remote Sensing for Environmental Monitoring III, vol. 11154, p. 111540E, International Society for Optics and Photonics, https://doi.org/10.1117/12.2534743, 2019.

Quegan, S., Le Toan, T., Chave, J., Dall, J., Exbrayat, J.-F., Minh, D. H. T., Lomas, M., D’Alessandro, M. M., Paillou, P., Papathanassiou, K., Rocca, F., Saatchi, S., Scipal, K., Shugart, H., Smallman, T. L., Soja, M. J., Tebaldini, S., Ulander, L., Villard, L., and Williams, M.: The European Space Agency BIOMASS mission: Measuring forest above-ground biomass from space, Remote Sensing of Environment, 227, 44-60, https://doi.org/10.1016/j.rse.2019.03.032, 2019.

515 Rafi, Z., Merlin, O., Le Dantec, V., Khabba, S., Mordelet, P., Er-Raki, S., Amazirh, A., Olivera-Guerra, L., Ait Hssaine, B., Simonneaux, V., Ezzahar, J., and Ferrer, F.: Partitioning evapotranspiration of a drip-irrigated wheat crop: Inter-comparing eddy covariance-, sap flow-, lysimeter- and FAO-based methods, Agricultural and Forest Meteorology, 265, 310-326, https://doi.org/10.1016/j.agrformet.2018.11.031, 2019.

Reichle, R. H. and Koster, R. D.: Bias reduction in short records of satellite soil moisture, Geophysical Research Letters, 31, L19501, https://doi.org/https://doi.org/10.1029/2004GL020938, 2004. 
Rosen, P. A., Kim, Y., Kumar, R., Misra, T., Bhan, R., and Sagi, V. R.: Global persistent SAR sampling with the NASA-ISRO SAR (NISAR) mission, in: 2017 IEEE Radar Conference (RadarConf), pp. 0410-0414, https://doi.org/10.1109/RADAR.2017.7944237, iSSN: 23755318, 2017.

Sakuratani, T.: A Heat Balance Method for Measuring Water Flux in the Stem of Intact Plants, Journal of Agricultural Meteorology, 37, 9-17, https://doi.org/10.2480/agrmet.37.9, 1981.

Schroeder, R., McDonald, K. C., Azarderakhsh, M., and Zimmermann, R.: ASCAT MetOp-A diurnal backscatter observations of recent vegetation drought patterns over the contiguous U.S.: An assessment of spatial extent and relationship with precipitation and crop yield, Remote Sensing of Environment, 177, 153-159, https://doi.org/10.1016/j.rse.2016.01.008, 2016.

Stamenković, J., Ferrazzoli, P., Guerriero, L., Tuia, D., and Thiran, J.-P.: Joining a Discrete Radiative Transfer Model and a Kernel Retrieval Algorithm for Soil Moisture Estimation From SAR Data, IEEE Journal of Selected Topics in Applied Earth Observations and Remote Sensing, 8, 3463-3475, https://doi.org/10.1109/JSTARS.2015.2432854, 2015.

Steele-Dunne, S. C., Friesen, J., and van de Giesen, N.: Using Diurnal Variation in Backscatter to Detect Vegetation Water Stress, IEEE Transactions on Geoscience and Remote Sensing, 50, 2618-2629, https://doi.org/10.1109/TGRS.2012.2194156, 2012.

Steele-Dunne, S. C., McNairn, H., Monsivais-Huertero, A., Judge, J., Liu, P.-W., and Papathanassiou, K.: Radar Remote Sensing of Agricultural Canopies: A Review, IEEE Journal of Selected Topics in Applied Earth Observations and Remote Sensing, 10, 2249-2273, https://doi.org/10.1109/JSTARS.2016.2639043, 2017.

Steele-Dunne, S. C., Hahn, S., Wagner, W., and Vreugdenhil, M.: Investigating vegetation water dynamics and drought using Metop ASCAT over the North American Grasslands, Remote Sensing of Environment, 224, 219-235, https://doi.org/10.1016/j.rse.2019.01.004, 2019.

Swanson, R. H.: Significant historical developments in thermal methods for measuring sap flow in trees, Agricultural and Forest Meteorology, 72, 113-132, https://doi.org/10.1016/0168-1923(94)90094-9, 1994.

Thompson, A. A.: Overview of the RADARSAT Constellation Mission, Canadian Journal of Remote Sensing, 41, 401-407, https://doi.org/10.1080/07038992.2015.1104633, 2015.

Torres, R., Snoeij, P., Geudtner, D., Bibby, D., Davidson, M., Attema, E., Potin, P., Rommen, B., Floury, N., Brown, M., Traver, I. N., Deghaye, P., Duesmann, B., Rosich, B., Miranda, N., Bruno, C., L’Abbate, M., Croci, R., Pietropaolo, A., Huchler, M., and Rostan, F.: GMES Sentinel-1 mission, Remote Sensing of Environment, 120, 9-24, https://doi.org/10.1016/j.rse.2011.05.028, 2012.

Vermunt, P. C., Khabbazan, S., Steele-Dunne, S. C., Judge, J., Monsivais-Huertero, A., Guerriero, L., and Liu, P.-W.: Response of Subdaily L-Band Backscatter to Internal and Surface Canopy Water Dynamics, IEEE Transactions on Geoscience and Remote Sensing, 59, 73227337, https://doi.org/10.1109/TGRS.2020.3035881, 2021.

Vreugdenhil, M., Wagner, W., Bauer-Marschallinger, B., Pfeil, I., Teubner, I., Rüdiger, C., and Strauss, P.: Sensitivity of Sentinel-1 Backscatter to Vegetation Dynamics: An Austrian Case Study, Remote Sensing, 10, 1396, https://doi.org/10.3390/rs10091396, 2018.

Xu, X., Konings, A. G., Longo, M., Feldman, A., Xu, L., Saatchi, S., Wu, D., Wu, J., and Moorcroft, P.: Leaf surface water, not plant water stress, drives diurnal variation in tropical forest canopy water content, New Phytologist, 231, 122-136, https://doi.org/https://doi.org/10.1111/nph.17254, 2021.

Ye, N., Walker, J. P., Wu, X., de Jeu, R., Gao, Y., Jackson, T. J., Jonard, F., Kim, E., Merlin, O., Pauwels, V. R. N., Renzullo, L. J., Rüdiger, 555 C., Sabaghy, S., von Hebel, C., Yueh, S. H., and Zhu, L.: The Soil Moisture Active Passive Experiments: Validation of the SMAP Products in Australia, IEEE Transactions on Geoscience and Remote Sensing, 59, 2922-2939, https://doi.org/10.1109/TGRS.2020.3007371, 2021.

Zhang, Z., Tian, F., Hu, H., and Yang, P.: A comparison of methods for determining field evapotranspiration: photosynthesis system, sap flow, and eddy covariance, Hydrology and Earth System Sciences, 18, 1053-1072, https://doi.org/10.5194/hess-18-1053-2014, 2014. 
https://doi.org/10.5194/hess-2021-459

Preprint. Discussion started: 17 September 2021

(C) Author(s) 2021. CC BY 4.0 License.

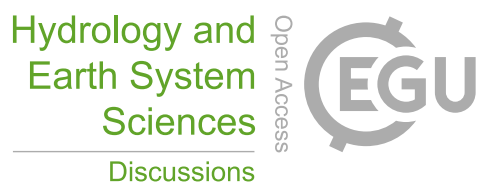

Zotarelli, L., Dukes, M. D., Romero, C. C., Migliaccio, K. W., and Morgan, K.: Step by Step Calculation of the Penman-Monteith Evapotranspiration (FAO-56 Method), Institute of Food and Agricultural Sciences, University of Florida, FL, USA, 2010.

Čermák, J., Kučera, J., Bauerle, W. L., Phillips, N., and Hinckley, T. M.: Tree water storage and its diurnal dynamics related to sap flow and changes in stem volume in old-growth Douglas-fir trees, Tree Physiology, 27, 181-198, https://doi.org/10.1093/treephys/27.2.181, 2007. 